\title{
Detection of calcium phosphate crystals in the joint fluid of patients with osteoarthritis - analytical approaches and challenges
}

\author{
Alexander Yavorskyy, ${ }^{a}$ Aaron Hernandez-Santana, ${ }^{a}$ Geraldine McCarthy ${ }^{b}$ and Gillian McMahon*a \\ DOI: 10.1039/b716791a
}

Clinically, osteoarthritis (OA) is characterised by joint pain, stiffness after immobility, limitation of movement and, in many cases, the presence of basic calcium phosphate $(B C P)$ crystals in the joint fluid. The detection of BCP crystals in the synovial fluid of patients with $O A$ is fraught with challenges due to the submicroscopic size of $B C P$, the complex nature of the matrix in which they are found and the fact that other crystals can co-exist with them in cases of mixed pathology. Routine analysis of joint crystals still relies almost exclusively on the use of optical microscopy, which has limited applicability for $\mathrm{BCP}$ crystal identification due to limited resolution and the inherent subjectivity of the technique. The purpose of this Critical Review is to present an overview of some of the main analytical tools employed in the detection of BCP to date and the potential of emerging technologies such as atomic force microscopy (AFM) and Raman microspectroscopy for this purpose.

\author{
${ }^{a}$ Bioanalytical Chemistry \& Diagnostics Group, \\ National Centre for Sensor Research, School of \\ Chemical Sciences, Dublin City University, \\ Dublin 9, Ireland. \\ E-mail: Gillian.McMahon@dcu.ie; Tel: +3531 \\ 7005914 \\ ${ }^{b}$ Division of Rheumatology, Mater \\ Misericordiae University Hospital, Eccles St, \\ Dublin 7, Ireland
}

\section{Introduction}

According to a recent report by a major healthcare insurer in Ireland, after heart bypass, the second most expensive treatment was knee replacement, and the third most common treatment was hip replacement. ${ }^{1}$ Today, osteoarthritis (OA) is the most common cause of damage to knee and hip joints with a final common pathway of cartilage degeneration and bone damage (Fig. 1). The prevalence of OA increases indefinitely with age, because the condition is not reversible. ${ }^{2}$ As a result, it incurs significant economic, social and psychological costs. ${ }^{3}$

Surgical interventions to correct altered biomechanics of large joints such as partial or total knee and hip joint replacement are the most common and effective

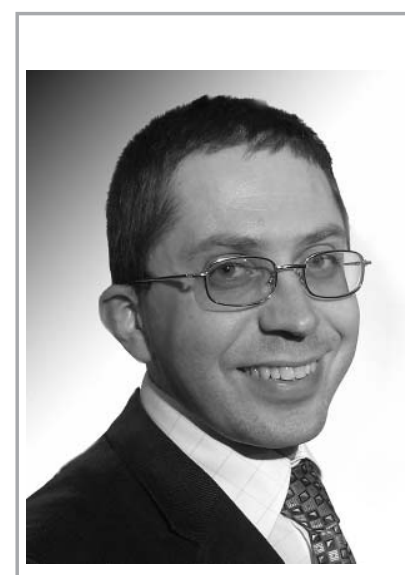

Alexander Yavorskyy
Dr Alexander Yavorskyy is a postdoctoral researcher in the Bioanalytical Chemistry \& Diagnostics Research Group where his focus is the development of methods for detection and quantification of basic calcium phosphate crystals in synovial fluid. He has an MSc in Pharmacy and $a$ PhD in Pharmacognosy from Lviv Medical University, Ukraine and a further MSc in Pharmaceutical Science from Tallaght Institute of Technology in Ireland.

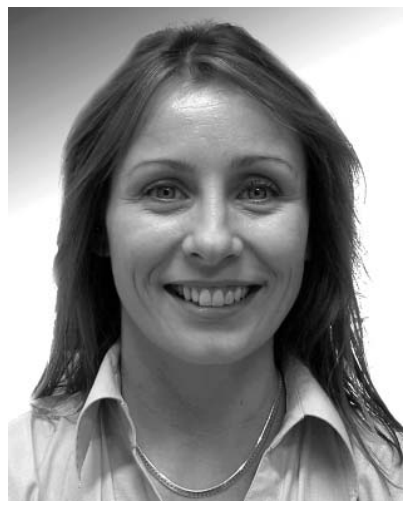

Gillian McMahon
Dr Gillian McMahon is head of the Bioanalytical Chemistry \& Diagnostics Research Group and a lecturer in analytical chemistry in the School of Chemical Sciences at Dublin City University. She has a $B S c$ in Analytical Science and a PhD in Biopharmaceutical Analysis. She has worked in the pharmaceutical industry both in the UK and in Ireland. Her research interests include analytical method development and novel sample clean-up techniques. 


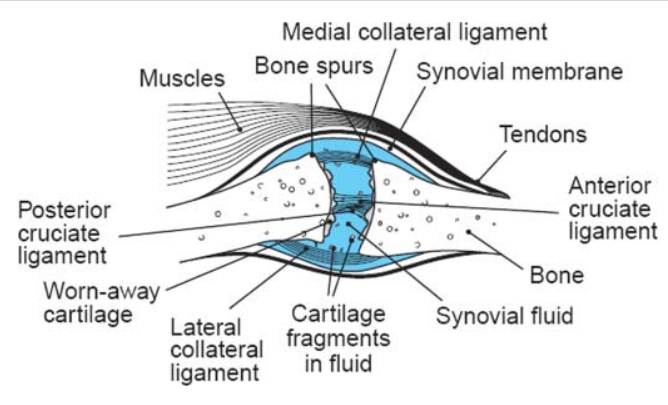

Fig. 1 A joint with severe osteoarthritis. In osteoarthritis, the cartilage becomes worn away. Spurs grow out from the edge of the bone, and synovial fluid increases. Altogether, the joint feels stiff and sore.

treatments for severely damaged joints by OA. ${ }^{4,5}$ To date, despite many studies, no treatment is known to change the course of symptomatic OA. ${ }^{6-8}$ Hence, currently available pharmacological therapies treat only the symptoms and help to reduce pain and to maintain or improve function. They usually involve intra-articular injection of steroids and non-steroidal antiinflammatory drugs. ${ }^{9-11}$

The accurate diagnosis of OA is the first important step in ensuring appropriate management of the disease. Misdiagnosis of OA can lead to unnecessary or inappropriate treatment, both of which can cause psychological stress to the patient. Currently, the diagnosis of OA is primarily based on overall clinical impression (history, physical examination and decision trees) and radiographic findings. ${ }^{12}$

Many radiological features that would previously have been dismissed as degenerative changes are now known to be manifestations or modifications of $\mathrm{OA}$ as a result of the influence of crystal deposition. Although the three principal crystal arthropathies may be distinguished radiologically there is an appreciable overlap between them and there are no exclusive hallmarks to allow an absolute diagnosis. ${ }^{13}$ Newer methods for aiding clinical diagnosis include magnetic resonance imaging and ultrasonography, ${ }^{14}$ and optical tomography ${ }^{15}$ which, like radiography, can reveal damage to the bone and/or cartilage but yield little or no data on the presence of associated crystals and the compositional changes in the synovial fluid.

Frequent discrepancies between symptoms and the results of radiographic examinations have been reported. ${ }^{16}$ Not all deformities and pain in and around the joints are associated with $\mathrm{OA}$, even if the patient is of an 'osteoarthritic age' and the joint shows 'osteoarthritic signs' on the X-ray, since there are many other types of arthritis with similar signs and symptoms. ${ }^{17}$ On the other hand, even if the underlying disease is OA, the symptoms and signs may be due to disorders secondary to the basic disease and the patient's complaints can be remedied more easily by physiotherapy and local injections. Therefore, current diagnosis of $\mathrm{OA}$ is quite subjective, complicated by multiple factors ${ }^{18}$ and would benefit from objective, validated diagnostic tools.

Despite the fact that less than $1 \%$ of the total expenditure on $\mathrm{OA}$ is presently spent on research, ${ }^{3}$ there is a growing body of knowledge about OA that may result in new treatment possibilities. Researchers are working to understand what role certain enzymes play in the breakdown of joint cartilage in OA and are testing drugs that block the action of these enzymes. Biochemical markers such as cartilage oligomeric protein, the serum level of Creactive protein, ${ }^{19}$ chondroitin sulfate and keratan sulfate epitopes, ${ }^{20}$ glycosaminoglycans and hyaluronan concentration ${ }^{21,22}$ might identify people at risk or in the earlier stages of the disease and allow for earlier intervention. ${ }^{23}$ Development of gene therapy for OA has also been explored for OA prevention and treatment. ${ }^{24}$ Effective treatment of OA, if it becomes available in the future, would have a major positive impact both on the individual as well as on society as a whole.

Another very promising approach for OA treatment is to target BCP crystals with novel agents. It is not clear whether BCP crystals are a cause or an effect in the condition but it is known that their concentration increases with the severity of the $\mathrm{OA}^{25-27}$ and hence drugs that could dissolve BCP crystals or prevent their formation is of great interest. This review will focus primarily on the methods and strategies currently used for the detection and quantification of BCP crystals since they represent a means of more accurate diagnosis of OA and a potential therapeutic target for the disease.

\section{Osteoarthritis and BCP crystals}

The identification of specific crystal types in synovial fluid is believed to be the most accurate way of diagnosing all common forms of crystal-associated arthritis. There are four main types of crystals that may be associated with joint and soft-tissue problems, due to their deposition in and around joints: these are basic calcium phosphate (BCP), calcium pyrophosphate dihydrate (CPPD), monosodium urate (MSU) and calcium oxalate $(\mathrm{CO})^{28,29}$ (see also Table 1$)$.

The origin of BCP crystals is not fully understood but some studies have suggested that both CPPD and hydroxyapatite (HA) crystals may be generated in cartilage osteoarthritis matrix vesicles. ${ }^{30}$ Calcium crystals have also been found in laser-irradiated cartilage. ${ }^{31}$

Despite the fact that the presence of both CPPD and BCP crystals in a single joint is not uncommon, there are clear and important differences between CPPD and BCP crystals in terms of their associated clinical patterns and etiologies. ${ }^{32} \mathrm{BCP}$ crystals are uniquely associated with $\mathrm{OA}^{33}$ and therefore their presence, if confirmed, can aid diagnosis of the disease. BCP crystals are reported to occur in up to $60 \%$ of patient synovial samples; ${ }^{34}$ however, this figure may actually be much higher since BCP crystals often simply evade discovery in synovial fluid due to their submicron size and difficult detection. ${ }^{35}$

Ample data support the role of BCP crystals in cartilage degeneration as their presence correlates strongly with the severity of radiographic $\mathrm{OA}^{25,33,36,37}$ and larger joint effusions are seen in affected knee joints when compared with joint fluid from OA knees without crystals. What is also known is that BCP crystals play an important role in the pathogenesis of OA and even more likely in the progression of disease due to their mechanical abrasive effects. ${ }^{27,28}$ The chronic synovial inflammation induced by calcium crystal deposits 
Table 1 Common crystal-associated arthropathies

\begin{tabular}{|c|c|c|c|}
\hline Crystals & Appearance & Size & Conditions \\
\hline \multirow[t]{3}{*}{ Basic calcium phosphate (BCP) } & Clumps and globules. & $1 \mathrm{~nm}^{43}$ (individual) & Osteoarthritis. \\
\hline & Amorphous-looking. & 5-20 $\mu \mathrm{m}(\text { clumps })^{44}$ & Milwaukee shoulder-knee syndrome. \\
\hline & $\begin{array}{l}\text { Appear as 'shiny coins' when clumped. } \\
\text { Non-birefringent }\end{array}$ & & Periarthritis/tendonitis \\
\hline \multirow{2}{*}{ Calcium pyrophosphate dihydrate (CPPD) } & Rod- or rhomboidal-shaped. & $1-20 \mu \mathrm{m}^{44,45}$ & Pseudogout. \\
\hline & Weakly positively birefringent & & CPPD deposition disease \\
\hline \multirow[t]{2}{*}{ Monosodium urate (MSU) } & Needle-shaped. & $2-30 \mu \mathrm{m}^{44,46}$ & Acute/chronic gout \\
\hline & Frequently intracellular. & & \\
\hline Calcium oxalate (CO) & $\begin{array}{l}\text { Strongly negatively birefringent } \\
\text { Tetragonal, bipyramidal, octahedral or } \\
\text { envelope shape }\end{array}$ & $15-20 \mu \mathrm{m}^{47}$ & Calcium oxalate-associated arthritis \\
\hline
\end{tabular}

could result in chronic polyarthritis, an advanced inflammatory process. ${ }^{38,39}$ Their pathogenic potential is further supported by their association with a distinctive form of gross destructive arthropathy of the shoulder called Milwaukee Shoulder Syndrome. ${ }^{40}$ Morgan, McCarthy and Molloy studied the molecular mechanisms leading to crystal-induced joint degeneration as a means of developing a rational approach for targeting the consequences of crystal deposition..$^{41,42}$ It was established that crystal-induced tissue damage is affected by degradative proteases, cytokines, chemokines, and prostanoids produced by cells stimulated by crystals. Despite much ongoing work in the field, there are continuing controversies concerning the relationship between calcium-containing crystals and OA and whether the crystals cause damage or are present as a result of joint damage.

The detection of BCP crystals in OA is particularly difficult due to the aforementioned reasons of their sub-micron dimensions and the challenges of finding them within the complex synovial fluid matrix. A further complication resides in the ability to distinguish them from the other crystals that can co-exist in synovial fluid such as CPPD and MSU, commonly associated with pseudogout and gout respectively. ${ }^{37,38,48,49}$

Fortunately, many analytical techniques that were previously confined to the research environment are now more readily available for clinical use. Many of these instruments are also now cheaper, portable and more sensitive than before. This offers analytical chemists new avenues of exploration in the quest to detect $\mathrm{BCP}$ crystals.

BCP crystals would be ideal targets for anti-OA therapy, since the acute symptoms of OA diseases are readily treated medically while the chronic effects of crys- tals are not. There are no effective drugs on the market to date which can inhibit the deposition or cause reabsorption of calcium-containing crystals. ${ }^{50}$

Some promising pre-clinical results for OA treatment were recently submitted by Cheung et al..$^{51}$ They reported that blocking the deposition of calcium-containing crystals by a new synthesised formulation of phosphocitrate can reduce cartilage degeneration in an animal model of OA. Treatment with the calcium crystal inhibitor reduced meniscal calcification and arrested OA progression. Other drug candidates include chondroitin, glucosamine sulfate, colchicine, bisphosphonates, hormones, green tea and ginger, and experimental treatments such as growth factors, gene therapy, matrix metalloproteinase inhibitors, nitric oxide and cytokines. ${ }^{52,53}$

With increasing activity in the research area and with the advent of new in vivo methodologies to study calcium deposition disease mechanisms, novel therapies that target the biological effects of these crystals at the molecular level may be on the way.

\section{Properties of synovial fluid}

The synovial fluid of natural joints normally functions as a biological lubricant as well as a biochemical pool through which nutrients traverse. Normal synovial fluid is clear, colourless and noticeably thick and stringy, like egg white (hence the name synovium 'with egg').

The exact chemical composition of synovial fluid is complex and to some extent poorly understood. The role of the fluid is to provide low-friction and low-wear properties to the cartilage surfaces. It is an ultrafiltrate of plasma with a higher viscosity due to glycoproteins and hyaluronic acid. It is worth noting that physicians have used injections of hyaluronic acid extracted from rooster combs directly into the synovial fluid in the knee as a treatment for OA of the knee for the past 20 years. ${ }^{57,58}$

The composition of synovial fluid relative to other human bodily fluids is shown in Table 2.

In conclusion, synovial fluid is a very complex biological matrix to work with analytically. It contains many different substituents that can interfere with the detection of BCP crystals and indeed other crystals.

\section{Properties of BCP crystals}

Because BCP crystals are non-acidic calcium phosphates, the term 'basic calcium phosphate' is often used to describe them. Owing to the fact that BCP is an umbrella term used to describe a few types of calcium phosphates, authors have tended to use different nomenclatures which can be confusing. As BCP is primarily composed of hydroxyapatite (HA), some authors focus their research on HA alone. Some other publications interchange the use of the terms BCP and HA, in some cases referring to the same compound and in other cases meaning the separate species.

BCP crystals are a group of ultramicroscopic crystalline substances primarily composed of hydroxyapatite $\mathrm{Ca}_{10}\left(\mathrm{PO}_{4}\right)_{6}$ $(\mathrm{OH})_{2}$, with smaller proportions of its precursors - octacalcium phosphate $\mathrm{Ca}_{8}\left(\mathrm{HPO}_{4}\right)_{2}\left(\mathrm{PO}_{4}\right)_{4} \cdot 5 \mathrm{H}_{2} \mathrm{O}$ and tricalcium phosphate $\mathrm{Ca}_{3}\left(\mathrm{PO}_{4}\right)_{2}$ (Table 3 ).

Octacalcium phosphate and tricalcium phosphate are commonly cited precursors to hydroxyapatite formation at physiological $\mathrm{pH}^{59,65} \mathrm{McCarty}$ et al. reported that natural pathologic calcifications contain several crystalline phases and that HA nucleation may be controlled by hydrolytic alteration of precursor calcium phosphate 
Table 2 Composition of synovial fluid relative to other human bodily fluids (modified from refs 54 and 55)

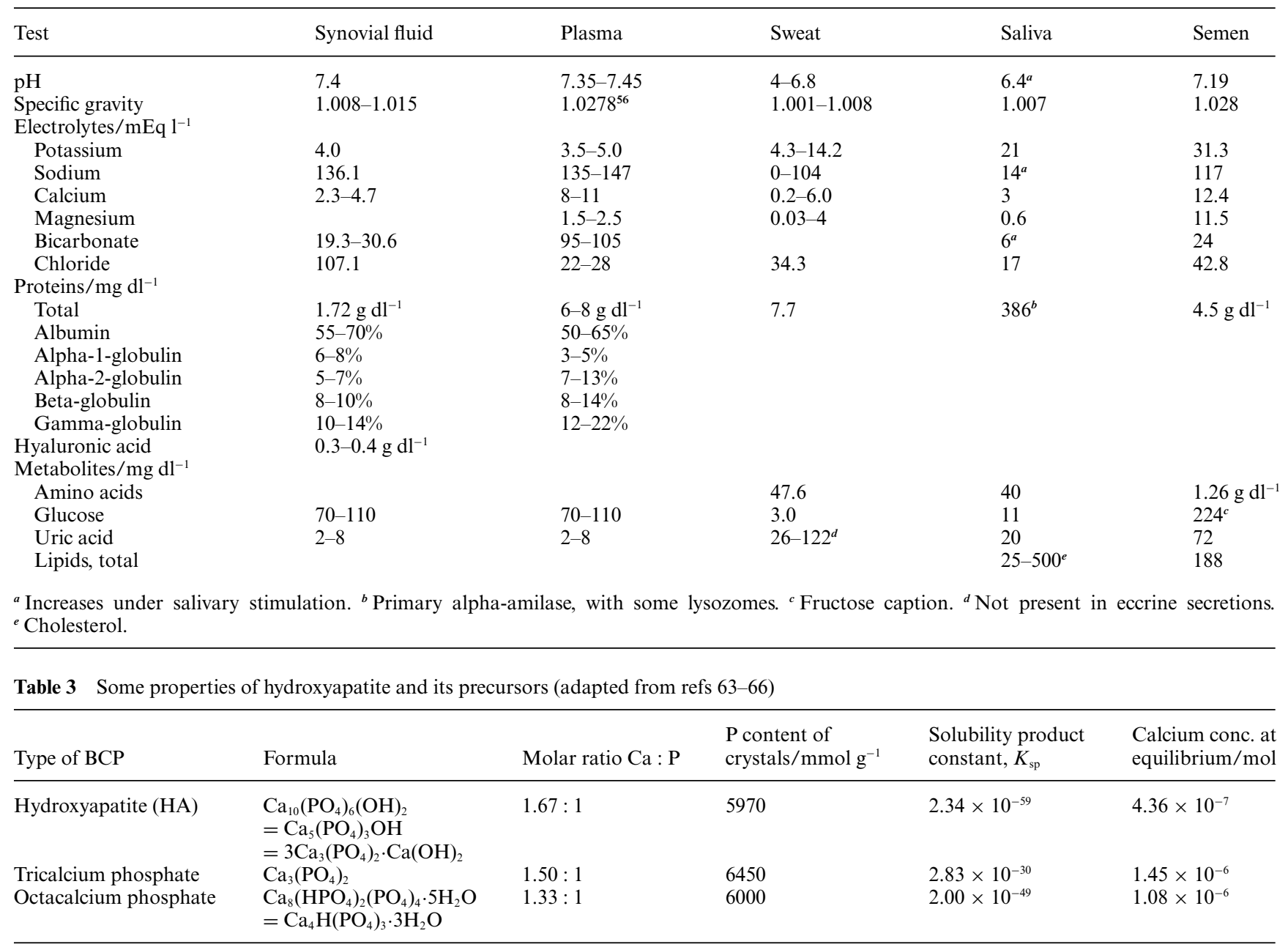

phases such as octacalcium or tricalcium phosphates. ${ }^{64}$ The precursors are considered to be transient mineral species and thus it is possible to assume that the physical properties of BCP in synovial fluid are dominated by those of HA.

Recent data suggest that magnesium whitlockite, another form of BCP in which magnesium is partly substituted for calcium, may also play a pathological role in arthritis. ${ }^{60}$

In terms of the stability of BCP compounds, HA appears to be the most thermodynamically stable under normal temperature and pressure and physiological conditions of $\mathrm{pH} 7.2-7.4 .^{59}$ The relative ratio of tricalcium and octacalcium phosphate to HA in synovial fluid is insignificant since they degrade much more quickly than HA. ${ }^{61}$ Hydroxyapatite crystals are naturally resistant to most chemical agents, except acidic solutions with a $\mathrm{pH}$ less than four and certain complexing agents.
Generally, calcium phosphate compounds have low solubility in aqueous environments. While the exact stoichiometry will have an effect, the order of solubility at physiological $\mathrm{pH}$ is tricalcium phosphate $>$ octacalcium phosphate $>$ hydroxyapatite. ${ }^{62}$

This poor solubility of calcium phosphate salts in biological fluids is one of the most important properties for determining the direction of many of their reactions such as dissolution, precipitation, hydrolysis, and phase transformation. HA solubility also plays a major role in biological processes that involve the formation and resorption of hard tissues as well as pathological calcifications. ${ }^{67}$ Owing to this extremely low solubility, normal synovial fluid can easily become supersaturated with BCP.

The kinetics of the crystal growth of hydroxyapatite over a range of $\mathrm{pH}$ (7.47.8) and at temperatures between 25 and $37.5^{\circ} \mathrm{C}$ has been studied by Meyer and
Nancollas. ${ }^{68}$ The rate of crystal growth was greatly enhanced by small increases in $\mathrm{pH}$ and temperature. However, the stoichiometry of the precipitating material, i.e. the type of BCP formed, was not found to be sensitive to $\mathrm{pH}$ and temperature under the conditions studied. The stability of HA crystals within the synovial fluid environment is of great importance since it is believed that they are far from being inert. Consequently, precautions have to be taken in the handling of specimens from joint fluid and of those made in the laboratory to avoid false positive/negative results during the analysis. Crystals are exposed to many physical forces during laboratory procedures. ${ }^{69}$

The two factors that are important in determining the activity of a crystal are the available surface area and surface contamination. Following general mechanisms of formation of crystalline materials, crystals found in synovial fluid apparently form via a phase change from liquid to 
Table 4 Analytical methods that have been used for BCP detection

\begin{tabular}{ll}
\hline Technique & Advantages \\
\hline $\begin{array}{l}\text { Imaging methods } \\
\text { Light and polarised microscopy }\end{array}$ & $\begin{array}{c}\text { Inexpensive, widely available and useful for the } \\
\text { larger crystals }(>1 \mu \mathrm{m}) \text { that can occur }\end{array}$ \\
Microscopy with staining & $\begin{array}{c}\text { Inexpensive, widely available and can identify } \\
\text { BCP crystal clumps }\end{array}$ \\
Multi-dimensional microscopy & $\begin{array}{c}\text { Coupling of multi-channel } \\
\text { micro-spectrophotometer and 3-D relief } \\
\text { imaging system to a microscope laser light } \\
\text { scattering spectroscope }\end{array}$ \\
Transmission electron microscopy & $\begin{array}{c}\text { Small sample size and can be used with electron } \\
\text { diffraction } \\
\text { Scanning electron microscopy } \\
\text { elemental analysis } \\
\text { Atomic force microscopy }\end{array}$ \\
Small sample size, minimal sample preparation. \\
Can exploit hardness and lattice features in \\
sample for detection and identification. \\
Chemical force microscopy may offer more \\
specificity
\end{tabular}

Disadvantages

Spectroscopic methods FTIR

Raman

Fluorescence

NMR/MRI

Other methods

Calcium and phosphorus analysis

X-Ray diffraction

Capillary electrophoresis

Radioassay

Ferrography
Accurate, used for automated pattern recognition methods

Accurate, water does not interfere, unique spectral signatures for each crystal type

With correct dyes, can be very sensitive and selective

Can visualise most types of pathologies including crystal depositions

Well-understood assays such as atomic spectrometry, UV-Vis spectrophotometry, etc., can be selective and sensitive

Accurate technique for unambiguous identification

Can be used for pattern recognition analysis of synovial fluids containing crystals

Allows semi-quantitative determination of $\mathrm{BCP}$ crystals

Provides separation of particles by size/magnetic properties
Inaccurate, non-specific and cannot detect $\mathrm{BCP}$ crystals. Polarised microscopy can aid detection of MSU and CPPD

Sensitive but non-specific, false positive results are frequent.

One dye is not enough to distinguish between the different types of crystals

Not widely available. No evidence of clear identification of synovial fluid crystals

Expensive, complex, not widely available, operator-dependent

Expensive, complex, relies on morphology

Operator-dependent, intricate to use on liquid samples, relies on morphology to an extent

Can be misinterpreted and water interferes in certain parts of the spectrum

Expensive, fewer library spectra available. Sample purification required to distinguish between various crystal types

Requires special equipment; dyes can be expensive, not suitable for in vivo use

Very expensive, cannot identify nature of crystal deposition. Operator-dependent

Practical only in analysis of dissociated crystals, other matter present in the fluid can interfere

Requires sample to be pure, dried and in sufficient quantity

Not applicable for direct separation of crystals

Involves radioactive reagents

Requires special sample preparation, only reflects general content of particles in synovial fluid solid where the solute concentrations balance within the solid-solution equilibrium (metastable region), i.e. above saturation point but below that at which crystal formation is inevitable. ${ }^{69}$ Very small particle size and therefore a high surface area to weight ratio contribute to crystal activity. Minor changes in physiological conditions might result in rapid phase transmission, i.e. crystal formation or dissolution.

Murugan and Ramakrishna have demonstrated that the bioresorbability rate of HA is highly dependent on particle size. ${ }^{70}$ The ionic dissolution of HA crystals with nanoscale morphological structure (with a mean particle size of $220 \mathrm{~nm}$ in diameter) which is close to that of biological HA was found to be higher than synthetic HA. Accordingly, it was suggested that the nano-hydroxyapatite has superior bioresorption and a chemical and crystallographic structure close to that of natural bone.

The unusual behaviour of bone-derived HA crystals may be explained by the crystalline structure of physiological HA. The analysis of bone mineral shows a $\mathrm{Ca}$ : $\mathrm{P}$ ratio ranging from $1.3: 1$ to 1.9 : 1 in comparison to the theoretical $\mathrm{Ca}$ : P stoichiometric ratio of $1.67: 1 .^{71}$ This deviation is mainly attributed to the carbonated groups present distorting the crystal structure of most biological HA. The surface properties of HA crystals are determined by surface charges. This may cause attachment of various proteins and other substances present in synovial fluid. The unique crystal/protein interac- tion seen with biological HA is absent with synthetic HA. ${ }^{72}$ Furthermore, recent investigations of physiological hydroxyapatite crystals have suggested that charge densities are not uniform but organised in the form of 'bands' (>10 nm) instead. ${ }^{71}$ Such features may lead to differences in quantitative and/or selective molecular binding.

\section{Analytical methods for BCP}

There are a number of analytical techniques that have been applied to the detection of BCP crystals in synovial fluid, either directly or indirectly. These are briefly summarised in Table 4 and will be discussed in the following sections in more detail. 


\section{Imaging methods}

Light and polarised microscopy. Imaging methods have long been used to examine synovial fluid samples for the presence of microcrystals. ${ }^{73}$ The ordinary light microscope with its limit of resolution of $c a$. $1 \mu \mathrm{m}$ is capable of detecting MSU, CPPD and CO crystals but is not capable of resolving $\mathrm{BCP}$ crystals unless they have aggregated into large clumps.

Compensated polarised light microscopy (CPLM) is a version of light microscopy that allows the identification of crystals by determination of the sign of their birefringence based on a colour change with rotation. It is used routinely to assist in the diagnosis of arthritis induced by
MSU and CPPD crystals ${ }^{74-76}$ since both of these crystal types exhibit some birefringence and also have easily differentiated shapes - needles and rods respectively (Fig. 2 and Fig. 3).

However, the method may not be sensitive or specific enough to serve as the standard upon which to base diagnosis ${ }^{77,78}$ since it can be very operatordependent. ${ }^{75,79-81}$ All MSU crystals are strongly birefringent and, hence, can be clearly distinguished by means of CPLM, whereas CPPD crystals are only weakly birefringent which leads to only one in five CPPD crystals having sufficient birefringence for detection. ${ }^{82}$ Also, since the resolution of CPLM is still limited to $c a$. $1 \mu \mathrm{m}$, the technique often fails to detect smaller crystals of MSU and CPPD and

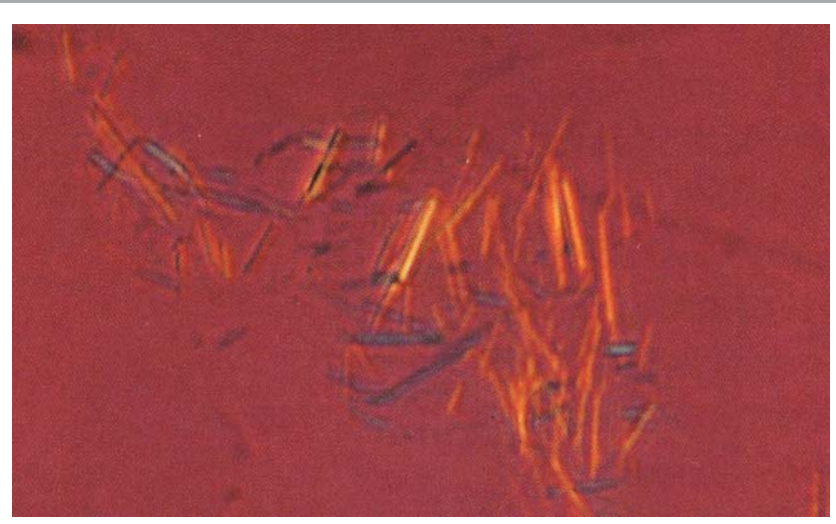

Fig. 2 A group of negatively birefringent monosodium urate (MSU) crystals aspirated from a tophus (magnification $\times 1400$, original magnification $\times 400$ ). Reproduced with permission from ref. 91. (Copyright 1992, Ciba-Geigy Corp.)

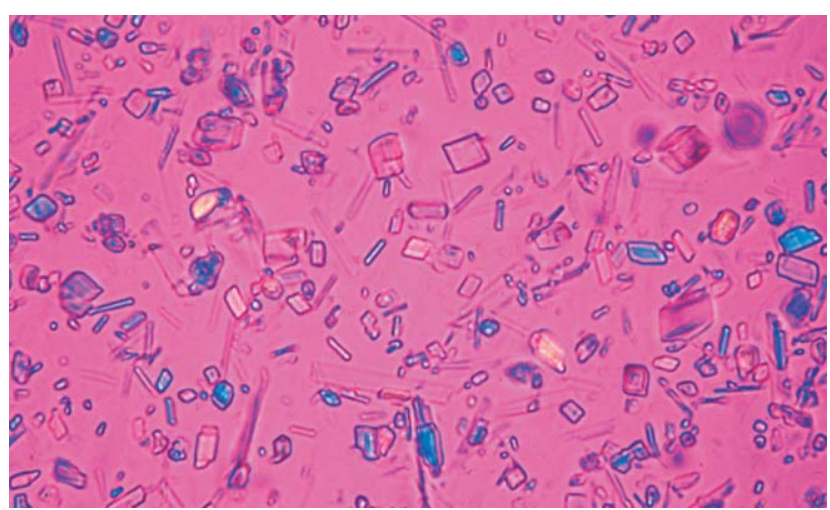

Fig. 3 Calcium pyrophosphate dihydrate (CPPD) crystals extracted from the synovial fluid of a patient with pseudogout viewed under polarised light microscopy. Note the fact that some of the particles do not appear to exhibit birefringence. Reproduced with permission from ref. 75. (Copyright 1999, BMJ Publishing Group Ltd.)

will definitely miss HA crystals unless they are aggregated. In contrast to MSU and CPPD, BCP crystals usually appear as an amorphous substance, which is not birefringent and cannot be seen under polarised light microscopy ${ }^{83}$ and they can easily be mistaken for artefacts or debris. ${ }^{84}$ Deposited corticosteroids that can have a variety of sizes and shapes as well as calcium oxalate crystals (Fig. 4) can contaminate specimens.

Crystals are not seen all of the time in cases of CPPD and MSU crystal disease, even by the most skilled observer. ${ }^{85,86}$ If examination of synovial fluid from a patient with acute crystal-related arthritis does not reveal either birefringent rods or needles, BCP crystals that are too small or too little in number to be identified by conventional techniques could be to blame. ${ }^{75,87}$

Microscopy with staining. Staining of joint fluids with dyes has been employed as an effective method to improve the detection of HA crystal clumps and small CPPD crystals, particularly those missed by CPLM. The Alizarin red $\mathrm{S}$ stain for permanent cytologic preparations has been recommended by many authors as a valuable complementary test to CPLM examination for the detection of CPPD crystals and HA crystal aggregates. ${ }^{88-90}$ Calcium forms a red chelation complex with Alizarin (Fig. 5).

Alizarin has greater sensitivity for the detection of CPPD crystals because they are stained regardless of how weakly or strongly birefringent they may be. ${ }^{92}$ In some reports such as that by Paul et al., staining was found to give a positive result in $100 \%$ of synovial fluids from patients later proven to have $\mathrm{HA}$ and/or CPPD deposition diseases. ${ }^{88}$ Gordon et al. found many discrepancies between the observers of the slides stained with Alizarin red S, and the effectiveness of such a screening test for BCP crystals was questioned. ${ }^{74}$ Much higher sensitivity for the Alizarin red $\mathrm{S}$ test was later observed by Shoji. ${ }^{93}$ He reported detectable threshold levels of HA and CPPD crystals in synovial fluid by Alizarin red $\mathrm{S}$ staining to be 0.1 and $0.5 \mu \mathrm{g} \mathrm{ml}^{-1}$, respectively. The staining gave a positive result in $100 \%$ of synovial fluids from patients with CPPD deposition disease, in $54 \%$ of the fluids from patients with OA, and in $39 \%$ of fluids from patients with rheumatoid arthritis. Shoji also claimed that Alizarin red S staining 


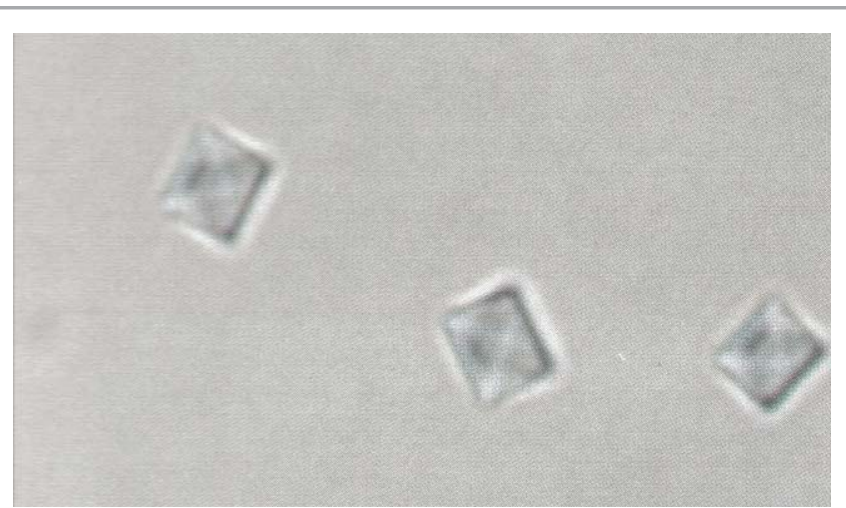

Fig. 4 Typical calcium oxalate (CO) crystals obtained from a synovial fluid effusion in a patient on long-term dialysis (magnification $\times 1800$, original magnification $\times 400$ ). Reproduced with permission from ref. 94. (Copyright 1992, Ciba-Geigy Corp.) was more sensitive than polarised microscopy and X-ray diffraction.

The sensitivity of the Alizarin red S staining test depends on both the concentration of the dye and the $\mathrm{pH}$ of the solution. As was reported by Shoji, the best results were obtained with an Alizarin red S concentration of $1.5-3.0 \%$ for HA and $2.0-3.0 \%$ for CPPD crystal detection. ${ }^{93}$ The optimal $\mathrm{pH}$ of the solution was 4.0 6.0 for HA and 4.0-5.5 for CPPD crystals. Analysis of the centrifuged synovial fluid sediment may facilitate identification of crystals and increases the specificity of Alizarin red in their identification..$^{90}$

HA and CPPD crystals are commonly found together in the same fluids and the Alizarin red S stain does not distinguish between different types of calcium compounds. Therefore, these can be distinguished only when typical crystal morphologic features are present. ${ }^{95}$

Another dye that has been used for crystal identification in synovial fluids is Diff-Quik - a commercial stain commonly used in histological staining to differentiate a variety of smears such as those from blood and vaginal samples. Selvi et al. used Diff-Quik ${ }^{\circledR}$ staining for identifying MSU and CPPD crystals on permanent mounted slides. ${ }^{96}$ Synovial fluid samples containing MSU crystals were all correctly diagnosed, but there were seven cases of false positives and negatives for CPPD crystals. This method was shown to be valuable for crystal identification in samples that were up to 12 months old. No data were reported on the use of Diff-Quik ${ }^{\circledR}$ for identification of HA crystals.

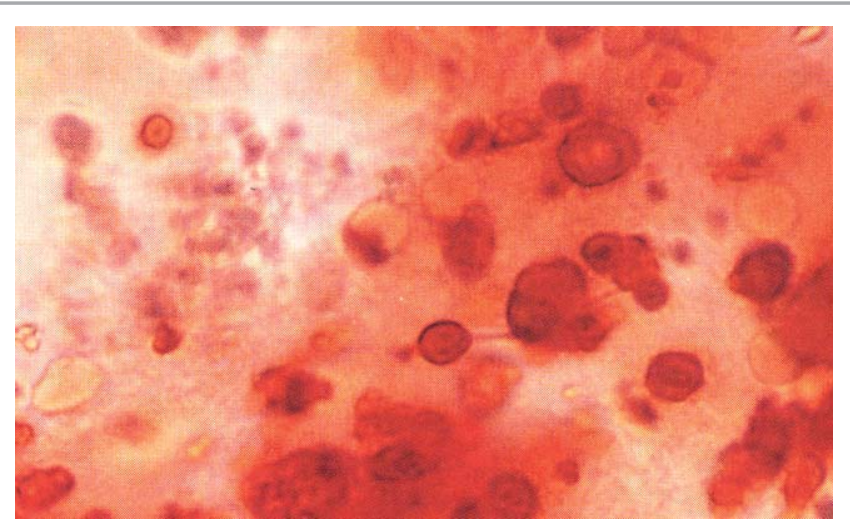

Fig. 5 A synovial fluid wet smear stained with Alizarin red S. The darker red deposits have the appearance of hydroxyapatitc accumulations. The specimen is from a patient with end-stage renal disease (magnification $\times 720$, original magnification $\times 200$ ). Reproduced with permission from ref. 94. (Copyright 1992, Ciba-Geigy Corp.)
The Gram stain method can be applied to almost any specimen and is one of the most commonly used techniques for the rapid diagnosis of bacterial infections. Petrocelli et al. demonstrated the usefulness of the Gram stain for MSU and CPPD crystal identification. ${ }^{97}$ This staining technique was used on specimens which more than two years later still showed pathological crystals.

Von Kossa staining is another wellknown method used in histology for the determination of calcium phosphate deposition in tissue sections ${ }^{98,99}$ and to characterise biological mineralisation of bone ${ }^{100}$ or renal calcium deposits. ${ }^{101}$ With the Von Kossa stain, calcium deposits appear deep grey or black. This stain has been successfully exploited in analytical systems such as BD BioCoat ${ }^{\mathrm{TM}}$ Osteologic $^{\mathrm{TM}}$ Discs. Studies of Bonewald et al., on the other hand, have demonstrated that Von Kossa staining alone is not appropriate for the identification and quantitation of bone-like mineral and, hence, other techniques such as X-ray diffraction, electron microscopy or FTIR should be utilised to verify the presence and quality of calcium phosphate phases. ${ }^{102}$

Multi-dimensional microscopy. A novel multi-dimensional microscope was recently reported to be capable of performing non-invasive real-time, in situ measurements on nanomaterials. ${ }^{103}$ This microscope can perform simultaneous measurements on both the 'visible' and 'invisible' particles in a solution sample, ranging in size from several nanometers to millimeters. In 2007, Zha et al. employed such a multi-dimensional microscope to determine the shape, size and distribution of solid particles in synovial fluids. ${ }^{104}$ Using compactness and integrated density as functions of the type and severity of knee OA and knee traumatic synovitis, no significant differences between the two diseases were observed. However, significant differences were observed between the knee OA, knee traumatic synovitis and the control subjects when the shape, size and size distribution of solid particles were observed in the synovial fluids and these closely correlated with the type and severity of the knee joint disease (Fig. 6).

Electron microscopy. Scanning electron microscopy (SEM) generates images by scanning a focused electron beam 

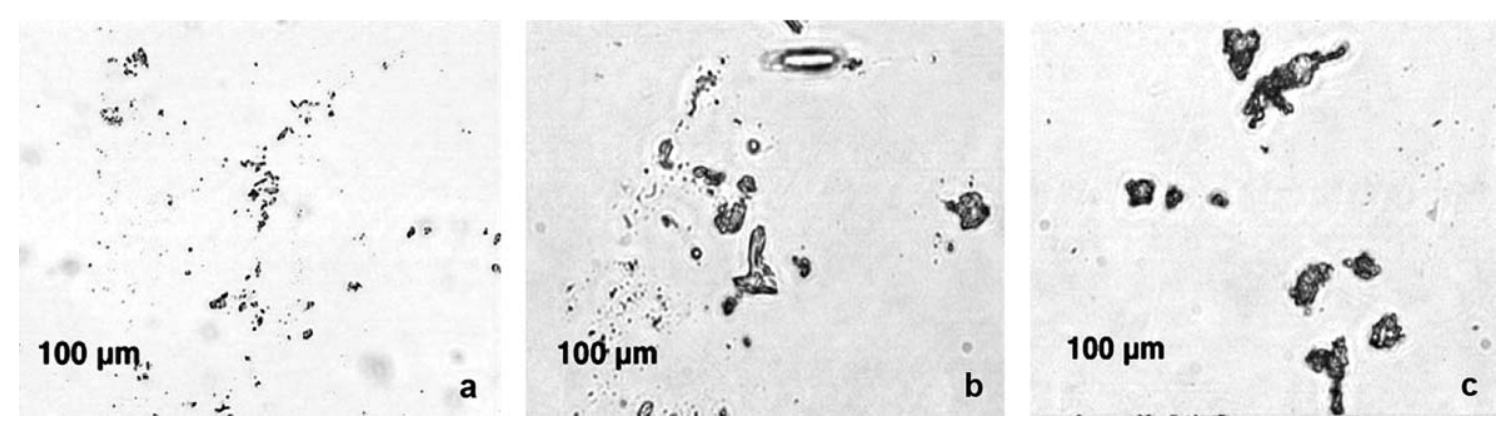

Fig. 6 Micrographs of solid particles in the synovial fluids of normal (a), osteoarthritis (b), and traumatic synovitis (c) subjects. Reproduced with permission from ref. 104. (Copyright 2007, Elsevier Ltd.)

across the surface of a sample. The electron beam interacts with the sample to produce various signals, including secondary electron emission, back-scattered electron cathodoluminescence and X-rays.

Sample preparation is relatively easy since most SEMs only require the sample to be conductive. The combination of higher magnification, larger depth of focus, greater resolution, and ease of sample observation makes SEM one of the most useful instruments in research today.

SEM has been used in the examination of all forms of tissue disorders in $\mathrm{OA}^{105}$ and the classification of cartilage wear and damage. ${ }^{106}$ In conjunction with other methods, SEM has been frequently used to characterise the morphology and distribution of crystal deposits in cartilage and synovial fluid. ${ }^{107-109}$ An electron microscope study carried out by Bardin et al. in 1987 showed that staining with Alizarin red permitted reliable detection of calcium microcrystals in articular fluid but only if the strongly positive results were taken into account. ${ }^{110}$ However, it was only positive in synovial fluids that contained high concentrations of crystals. As fluids with CPPD crystals may also give positive Alizarin red staining, it is not a definitive method for BCP crystals. Doyle and Crocker developed a series of methods that, in the case of synovial fluids, allows the rapid preparation of fresh specimens for electron microscopic examination, a procedure that previously took up to $48 \mathrm{~h}^{111}$

Despite of all the advantages of SEM, there are still difficulties with visualising synovial samples directly due to the presence of large amounts of biological residues that can burn and coagulate under the high voltages required for imaging.
To remove this problematic organic material, negative pressure filtration of synovial fluids was used by Doyle and Crocker ${ }^{111}$ to collect crystals. Low temperature microincineration of the synovial fluid samples assisted in removing organic material to leave the crystals exposed for SEM examination. However, while SEM has proved to be useful for the identification of microcrystalline material in synovial fluid, it can be impractical for routine diagnostic use because it needs specialised training and the equipment is expensive. Also, not all SEM instruments have the required resolution for seeing individual HA crystals.

Electron probe microanalysis (EPMA) allows the determination of the relative amounts of the crystal elements and hence the $\mathrm{Ca}$ : $\mathrm{P}$ molar ratio which is of important diagnostic value. ${ }^{82}$ In one study, LiYu et al. utilised EPMA for the identification of crystals/particles seen in synovial fluid rice bodies. ${ }^{112}$ For one patient, they reported that the $\mathrm{Ca}: \mathrm{P}$ molar ratio of $1: 1$ indicated the presence of CPPD crystals while a ratio of $1.4: 1$ indicated the presence of carbonate-substituted HA.

Ali used electron microscopy coupled with electron probe analysis and revealed the presence of various calcium phosphate crystals in joint tissues and fluids which were too small to be detected by X-rays of human joints or by light microscopy of joint tissues. ${ }^{113}$ 'Cuboid' crystals were found near the surface zone of articular cartilage and appeared to be a variant of magnesium-containing hydroxyapatite (whitlockite) and needle-shaped HA crystals were also found on the cartilage surface.

EPMA has been found to be useful in the analysis of initial hydroxyapatite formation in calcifying cartilage, ${ }^{114}$ evaluation of the crystallographic structure of HA/collagen composites ${ }^{115}$ and crystal deposition identification. ${ }^{116}$

Transmission electron microscopy (TEM) is another useful technique for studying crystal-related arthropathies. It can visualise crystals too small to be seen by light microscopy and allows further study of crystal-cell interaction. However, it can also display various artefacts, for example silicon-containing particles from glassware can be similar in appearance to some CPPD or hydroxyapatite crystals. ${ }^{17}$ It also has been revealed by TEM that CPPD and HA crystals are frequently associated with granular materials, presumably protein coating. ${ }^{118}$ Bonavita et al. reported that the diagnosis of HA deposition could be made based on the results of TEM examination when needleshaped crystals 75-250 $\AA$ in diameter are seen and electron probe elemental analysis gives a $\mathrm{Ca}: \mathrm{P}$ ratio of $1.6: 1 .{ }^{119}$

TEM and high-resolution transmission electron microscopy (HRTEM) were used by Suvorova and Buffat in order to investigate the composition of individual HA crystals, their sizes, morphology and structure. ${ }^{120}$ The authors found HRTEM and microdiffraction to offer distinct advantages over SEM and X-ray diffraction for the investigation of small particles and mixtures of calcium phosphates.

In 2006, Nero et al. used light microscopy with Alizarin red staining, TEM and energy dispersive spectroscopy in order to identify and characterise crystals. $^{121}$ With TEM, the authors were able to identify BCP crystals in synovial fluid samples which were previously unseen by light microscopy. They concluded that microcrystals were a universal 
finding in the synovial fluids of patients with OA.

\section{Scanning probe microscopy.} Scanning probe microscopy covers several related technologies for imaging and measuring surfaces on a fine scale, down to the level of atoms.

Atomic force microscopy (AFM) may provide a simple yet powerful technique for the detection of microcrystals in synovial fluid taken from patients with crystal-induced arthritis. In 1995, Blair et al. identified MSU, CPPD, HA, octacalcium phosphate and cholesterol crystals with $\mathrm{AFM}^{122}$ (Fig. 7). The surface topology, lattice parameters and irregularities at the crystal surfaces imaged by AFM were found to be consistent with those obtained by TEM and X-ray diffraction studies. In addition, AFM images revealed that some specimens contained microcrystals that were undetected by polarised light microscopy and/or TEM. Chemical force microscopy (CFM), where the tip of the AFM microscope is coated with a material that is selective for the target molecule, may offer new opportunities for more specific methods for the detection of crystals in synovial fluid. ${ }^{123}$

\section{Spectroscopic methods}

Exploitation of optical properties such as absorbance, reflectance and transmittance of synovial fluid has found many applications in OA research.

FTIR. Infrared spectroscopy (IR) or Fourier-transform infrared spectroscopy (FTIR) is a widely used analytical technique. It provides the basis for accurate and cost-effective quantification of numerous components in biofluids such as whole blood, plasma or serum, synovial fluid, aqueous humour, saliva and urine. The methodology is usually reagentless, fast and readily automated. Infrared spectroscopic analysis is not hindered by the physical state of the sample and measurements can be made in a variety of instrument configurations. ${ }^{125}$ IR spectrometers can be made to be compact, rugged, relatively inexpensive and user-independent, making the technology capable of point-of-care operation. ${ }^{126}$
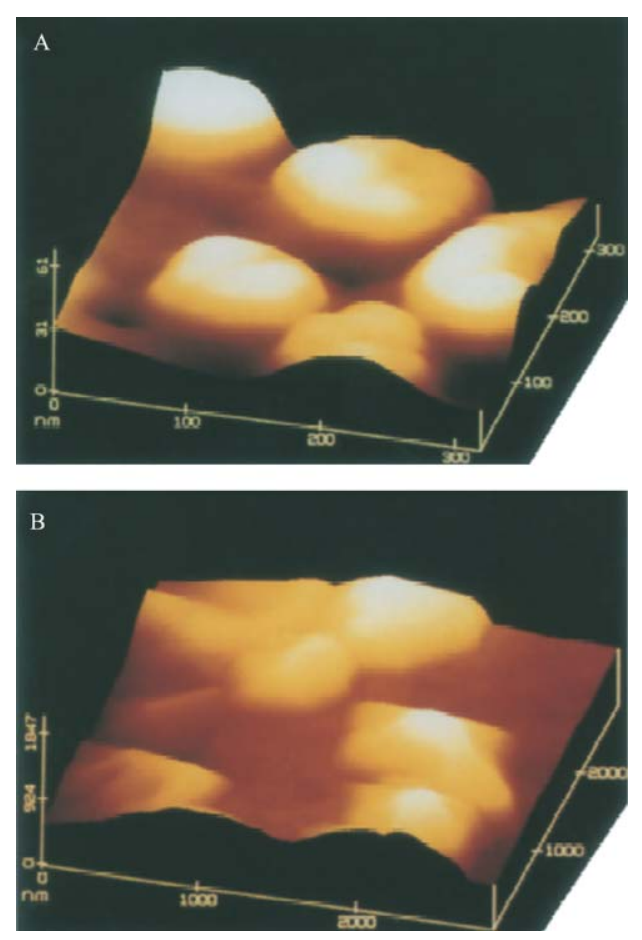

Fig. 7 AFM images of HA and CPPD crystals from a patient with HA-induced arthritis. (A) HA crystals clump to form pseudospherical microaggregates (100-150 nm in diameter). (B) CPPD crystals shown here were an unexpected finding in this specimen. Reproduced with permission from ref. 122. (Copyright 1995, Elsevier Ltd.)

The FTIR spectrum of HA has been reported $^{127}$ (Fig. 8) but routine analysis using this method is impractical unless the crystals are first isolated from the biological matrix. Starting from the hypothesis that the transition from a healthy to an arthritic joint should be accompanied by a change in the composition of the synovial fluid, clinical diagnostic methods have been applied under the premise that the IR 'molecular fingerprint', combined with suitable pattern recognition methods can distinguish 'normal' synovial fluid specimens (Fig. 9) from those with specific disease types. Eysel et al. have used FTIR to investigate synovial fluid and serum samples from patients suffering from OA, spondyloarthropathy or rheumatoid arthritis. ${ }^{128}$ Significant differences in the composition of the synovial fluid were found (Fig. 10). Based on linear discriminant analysis, the authors were able to distinguish between the diseases (and controls) with 96.5\% accuracy.

Similar results were obtained by Ziegler et al. in $2002 .{ }^{129}$ During an IR investigation of the 22 synovial fluid samples aspirated from the temporomandibular joints (12 OA and 10 rheumatoid arthritis), a distinct intensity difference between the absorption spectra from arthritic and noninflamed temporomandibular joints was noted (Fig. 11).

Shaw and co-workers have used IR for synovial fluid analysis and diagnosis of arthritic disease. ${ }^{130-132}$ In one paper, they carried out an investigation based upon the obtained IR spectra of synovial fluid films dried onto glass substrates. ${ }^{130}$ In general the spectrum was dominated by features that correspond to protein absorptions ( $\mathrm{N}-\mathrm{H}$ stretching and bending and $\mathrm{C}=\mathrm{O}$ stretching vibrations), lipid $\mathrm{CH}_{2}$ and $\mathrm{CH}_{3}$ modes, and carbohydrate $\mathrm{C}-$ $\mathrm{O}$ stretching. The authors have also successfully exploited the near-IR region of the spectrum - absorption patterns from 2000-2400 $\mathrm{cm}^{-1}$ were used - to diagnose the various forms of arthritis. ${ }^{131}$

They concluded that the applications of IR methods may provide analytical information indirectly since the main strength of the technique lies not in its ability to identify novel disease markers, but rather in its ability to carry out multivariate pattern recognition. Inaccuracies of the FTIR approach are linked to the fact that some rheumatoid arthritis patients can also be affected by OA, and the 


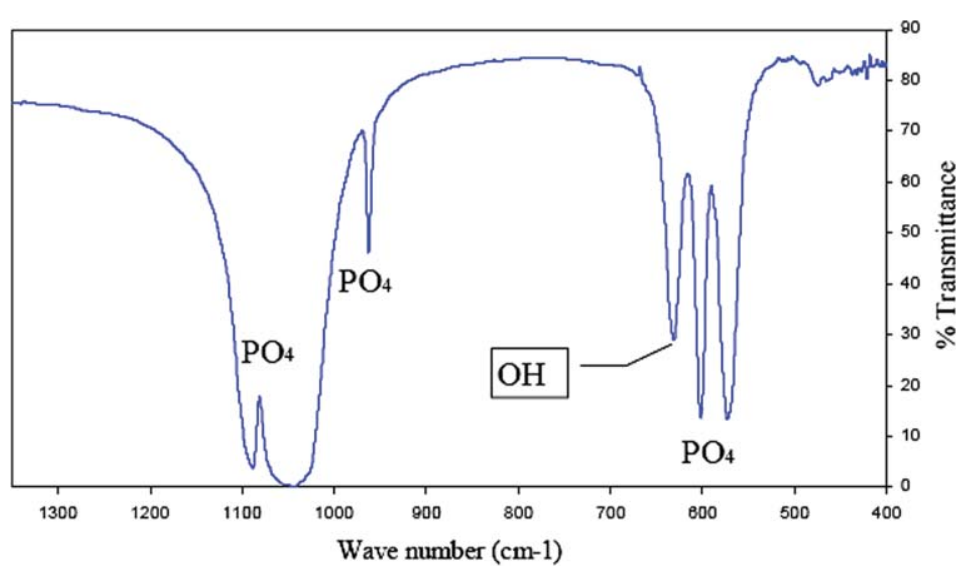

Fig. 8 Infrared spectrum of hydroxyapatite. Reproduced with permission from ref. 127. (Copyright 2007, Elsevier Ltd.)

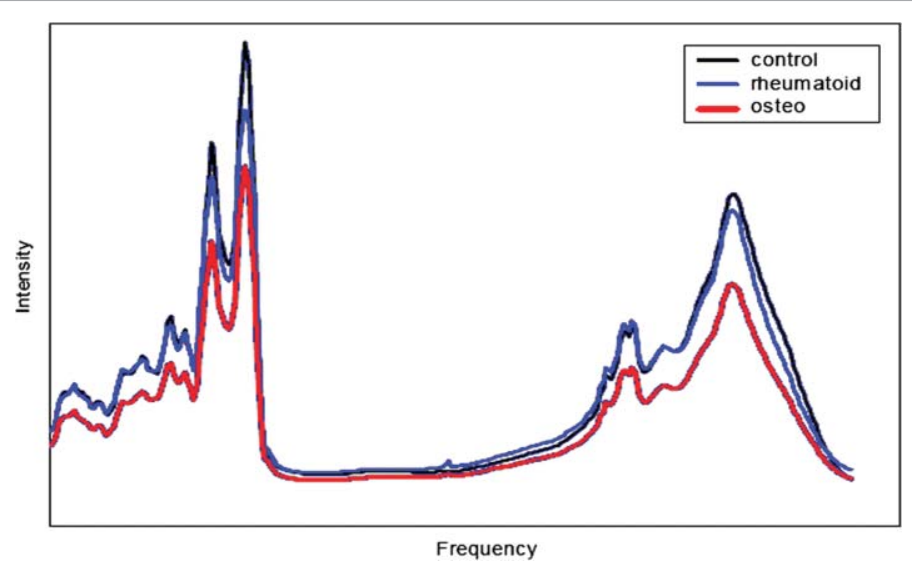

Fig. 9 Caption typical infrared spectra of synovial joint fluid. Reproduced with permission from ref. 124. (Copyright 2004, IEEE.)

synovial fluid sample might therefore be legitimately classified in either category. However, it was subsequently suggested that the natural variability (uncorrelated to any disease state) between patients limits the interpretation of the differences that do exist. ${ }^{133}$

To avoid the variability above between patients, a newer approach for OA diagnosis focused on BCP crystals which have a unique IR molecular fingerprint. The hydroxyapatite bands of interest in the infrared region are due to hydroxyl $\left(\mathrm{OH}^{-}\right)$, carbonate $\left(\mathrm{CO}_{3}{ }^{2-}\right)$ and phosphate $\left(\mathrm{PO}_{4}{ }^{3-}\right)$ moieties. The absorption spectra of $\mathrm{HA}$ and CPPD crystals are different. ${ }^{134}$ This can aid correct diagnosis of crystal-related disease affecting the joint from which the aspirate is drawn.
These results suggest that the FTIR analysis of certain regions of the spectrum may be sufficient to allow the categorising of certain patient types based on spectral pattern recognition. However, the application of such an approach requires thorough statistical validation in each case due to considerable normal variation between individuals within the populations (pathologies) and frequent occurrence of mixed pathologies.

Raman. Raman spectroscopy has emerged in the past years as an extremely powerful technique for probing the molecular composition of a wide range of materials. ${ }^{135}$ Raman allows one to derive detailed and specific information on a molecular level that other laser

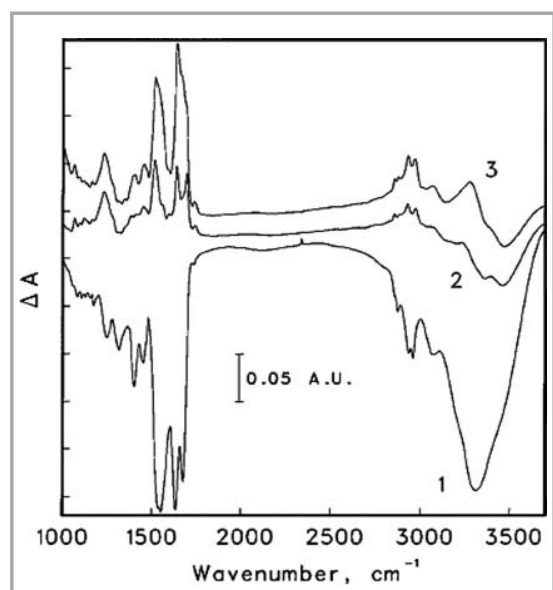

Fig. 10 Infrared difference spectra generated by the subtraction of the classaverage spectrum of non-arthritic synovial fluid films from the class-average spectra of synovial fluid films for (1) osteoarthritis (2) rheumatoid arthritis and (3) spondyloarthropathy. Reproduced with permission from ref. 128. (Copyright 1997, John Wiley \& Sons, Inc.)

spectroscopic methods can provide only to a limited extent. Modern Raman is usually reagentless, the instruments are relatively small and the technique is non-invasive.

The use of Raman spectroscopy in biological investigations presents several advantages, especially when compared to IR methods. ${ }^{136}$ Raman microspectroscopy is able to probe samples at the micrometer scale, and water causes very little interference. Both phases can therefore be simultaneously investigated in a fresh tissue or aqueous solution (like synovial fluid) in a non-destructive way. ${ }^{177,138}$ In addition, conventional silica optical fibres transmit both the laser and Raman-shifted light well, making portable Raman a reality. The main disadvantage of Raman is the background fluorescence that can occur with biological samples, especially from proteins. However, this problem can be circumvented by judicious choice of laser source.

A recent paper by Matousek and Stone obtained non-invasive Raman spectra of calcified materials buried within a chicken breast tissue slab $16 \mathrm{~mm}$ thick using NIR excitation. ${ }^{139}$ McGill, Dieppe and co-workers applied Raman microscopy to the identification of crystals in pathological samples from patients with crystal deposition disease. ${ }^{140}$ Reference Raman spectra were obtained for synthetic MSU 

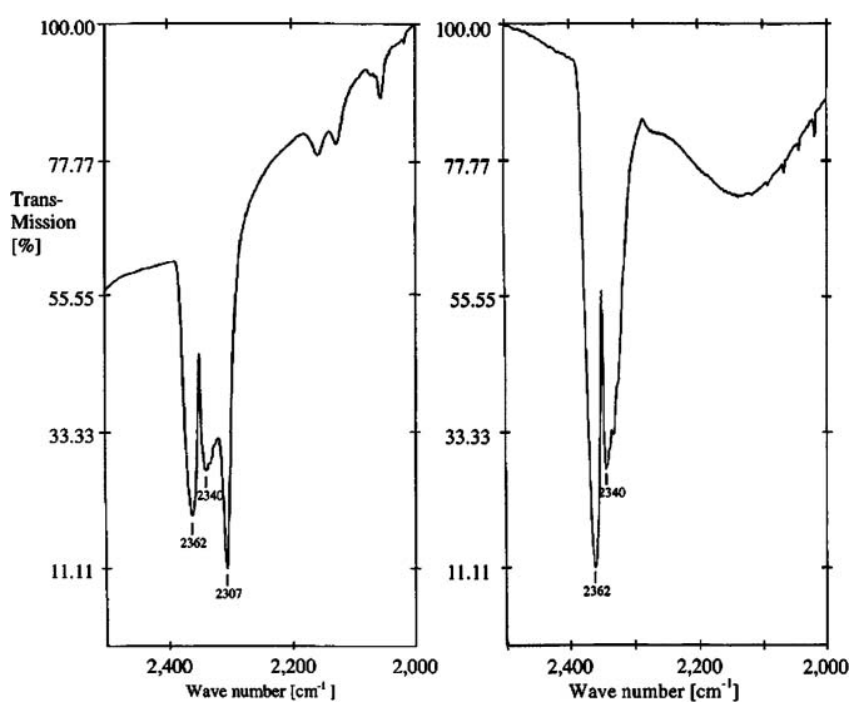

Fig. 11 IR spectra of osteoarthritis and rheumatoid arthritis synovial fluid samples. Both are transmission spectra in the range of 2500 to $2000 \mathrm{~cm}^{-1}$. A reference spectrum of water was subtracted from each sample. Bands at 2362 and $2340 \mathrm{~cm}^{-1}$ result from $\mathrm{CO}_{2}$ vibrations. Reproduced with permission from ref. 129. (Copyright 2002, Elsevier Ltd.)

(at $631 \mathrm{~cm}^{-1}$ ) and CPPD crystals (at $1050 \mathrm{~cm}^{-1}$ ) and these were compared to patient samples which were chosen such that there would be no doubt about the presence or nature of the deposits. The authors concluded that the method has considerable potential and that issues of low intensity and poor signal/noise ra- tios could be overcome. Using modern Raman instrumentation and NIR excitation, studies by our group have confirmed that HA, CPPD and MSU crystals do exhibit different Raman spectra and that the crystals could therefore be easily distinguished from each other based on spectral analysis (Fig. 12). The assumption that $\mathrm{BCP}$ is primarily composed of $\mathrm{HA}$ is futher evidenced by the fact that their Raman spectra are so closely related in this same figure.

With further developments, both Raman and FTIR spectroscopy could overcome the problems of other analytical techniques and provide a powerful new tool for the investigation of crystal deposition disease and physiological mineralisation. ${ }^{141}$ Currently, Raman is best utilised as a tool to distinguish between crystals that can be found in synovial fluids.

Luminescence. Fluorescence imaging is used extensively in chemical and biomedical analysis schemes. Many of these assays are based on the introduction of a fluorescent species as a marker, stain, dye or indicator. However, the intrinsic fluorescence of biomolecules poses a problem when visible light (350-700 nm)absorbing fluorophores are used because of high tissue absorption and scatter. As in Raman, near-infrared (NIR) fluorescence $(700-900 \mathrm{~nm})$ detection avoids the background fluorescence interference of natural biomolecules, providing a high contrast between target and background tissues.

NIR fluorophores have wider dynamic range and minimal background as a result of reduced scattering compared with

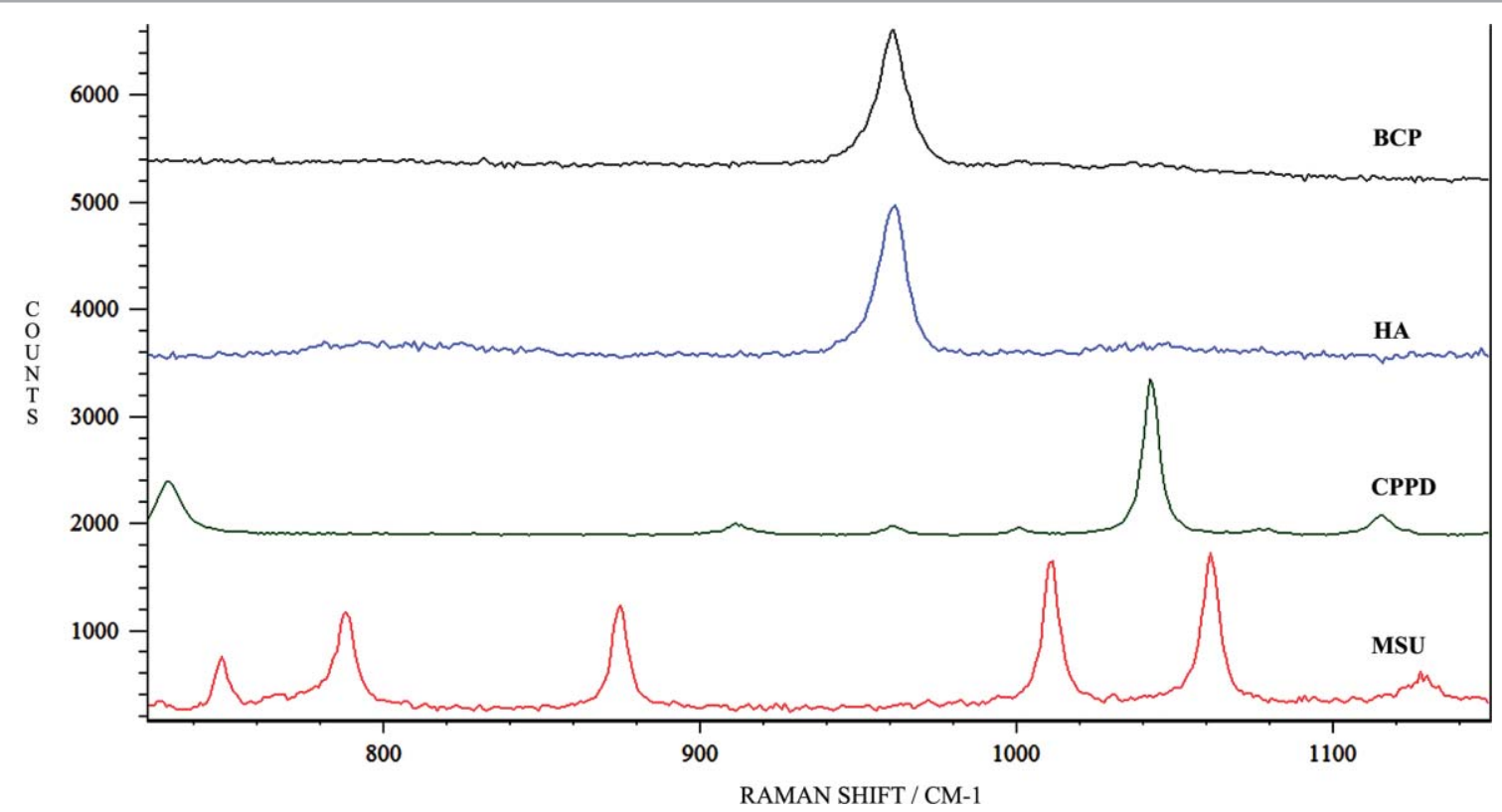

Fig. 12 Raman reference spectra of synthetic BCP, HA, CPPD and MSU crystals. 


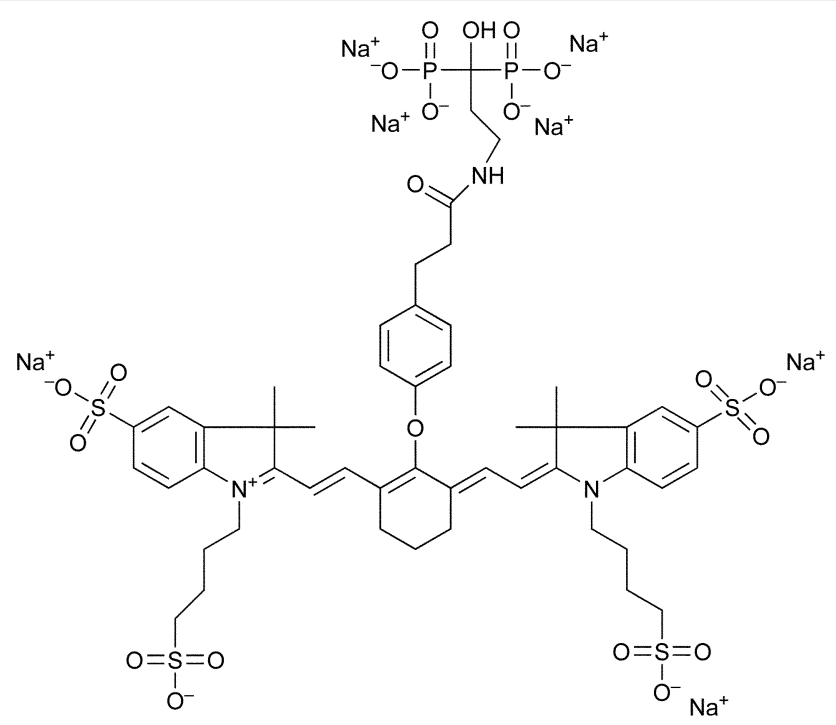

Fig. 13 Pamidronate-IRDye78.

visible fluorescence detection. They also have high extinction coefficients and quantum yields and hence can be detected with high sensitivity. The NIR region is also compatible with solid-state optical components, such as diode lasers and silicon detectors, facilitating miniaturisation of such systems. NIR fluorescence imaging is becoming a non-invasive alternative to radionuclide imaging in vitro and in small animals. Bisphosphonates are well-known analogues of endogenous pyrophosphate that have a strong affinity for bone mineral and thus bind tightly to HA crystals. ${ }^{142}$

Apart from their medical use in osteoporosis, bisphosphonates have also found analytical applications. In 2001, Zaheer et al. synthesised a NIR fluorescent bisphosphonate derivative (named Pamidronate-IRDye78 or Pam78, Fig. 13) that produced rapid and specific binding to HA in vitro and in vivo and exhibited peak absorption at $771 \mathrm{~nm}$ and peak excitation emission at $806 \mathrm{~nm} .{ }^{143}$ Pam78 was later used for the non-isotopic detection of osteoblastic activity in vivo. ${ }^{144}$

A simple and rapid animal model of focal calcification in breast cancer tumours involving Pam 78 has been developed and validated by Lenkinski et al. ${ }^{145}$ Tumours implanted with HA crystals displayed bright, focal, NIR fluorescence in the area of crystal implantation. Control tumours, grown in the same animal and implanted with calcium oxalate, did not display any near-infrared fluorescence, even along the needle track used for crystal implantation.

Based on Zaheer's research, Kossodo et al. developed a commercial NIR bisphosphonate imaging agent for the technique of fluorescent molecular tomography called OsteoSense ${ }^{\mathrm{TM}} 680$ that binds to HA with high affinity in vitro and in vivo. ${ }^{146}$ OsteoSense ${ }^{\mathrm{TM}} 680$ was applied to the non-invasive, 3-D molecular imaging of areas of microcalcifications and bone growth and resorption. ${ }^{147}$

More recently, De Grand et al. applied ICG-labelled polystyrene divinylbenzene beads and Pam78-labelled HA crystals to the evaluation of microcalcifications in a breast cancer model. ${ }^{148}$ Absorbance, scatter and background fluorescence were imaged using a reflectance optical imaging system. Hale et al. described a method for rapid quantitative assessment of in vitro mineralisation in osteoblast-like cell cultures by direct fluorescence analysis of calcein bound to HA. ${ }^{149}$ The application claimed to be sensitive, showing significant differences in bound calcein fluorescence over very small changes in HA concentration.

NMR/MRI. Nuclear magnetic resonance (NMR) is an analytical technique that can now be applied to the human body or parts thereof as magnetic resonance imaging (MRI). MRI is a multiplanar image method based on the interaction between radiofrequency electro- magnetic fields and certain atomic nuclei in the body (usually hydrogen), after the body has been placed in a strong magnetic field. It is particularly useful in detecting soft-tissue damage and evaluation of inflammatory disease and traumatic conditions. ${ }^{150}$ MRI is a superb technique for viewing soft-tissue structures without radiation risks ${ }^{151}$ but it poorly resolves bone mineral, ${ }^{152}$ has low sensitivity for detecting calcifications and can display only massive deposition rather than individual crystal deposition. The cost of the equipment and its upkeep and the time required to perform the procedure make it the most expensive imaging technique currently used. ${ }^{151}$

MRI has been seen recently as having potential for evaluation of joints in OA due to its ability to evaluate morphology and integrity of the articular cartilage. It also provides a direct image of the soft tissues around the joint, ${ }^{153}$ osynovial-based processes such as rheumatoid arthritis and crystal deposition disorders in a variety of joints. ${ }^{154-156}$ Stray-field techniques are reported for ${ }^{31} \mathrm{P}$ studies of solids for a variety of compounds including bone and calcium hydroxyapatite. ${ }^{157,158}$

Because MRI can depict many of the same findings of osteoarthritis as those depicted on radiographs, radiography remains the imaging method of choice in the diagnosis of OA due to its costeffectiveness and ready availability.

\section{Other methods}

Calcium and phosphate analysis. BCP is a mix of crystalline substances that are comprised of calcium, phosphate and sometimes hydroxyl and/or carbonate ions. The analytical determination of the concentrations of these ions could provide quantitative or semi-quantitative data for BCP crystals in synovial fluid.

Colorimetric/spectrophotometric methods are widely used for determining the concentration of various elements in biological fluids. The methods usually involve adding a reagent to the fluid, which forms a coloured complex with the specific element to be detected. The complex then absorbs light at a characteristic wavelength and the intensity of that absorption can be related to concentration of the element.

There are numerous colorimetric indicators of calcium such as eriochrome 
blue, ${ }^{159} o$-cresolphthalein complexone, ${ }^{160}$ Arsenazo III. ${ }^{161,162}$ and Phosphonazo III.

The two most common assays for orthophosphate are the molybdate 'yellow' and molybdate 'blue' methods. ${ }^{163,164}$

One problem with using this approach for BCP crystals is the effect of interferences on the absorption spectrum of the complex. For instance, magnesium often interferes in assays for calcium, though this can sometimes be minimised by controlling the $\mathrm{pH}$ of the reaction. High turbidity of synovial fluid samples due to high content of biological ingredients (e.g. hyaluronan) also complicates the direct determination of calcium without additional crystal purification/extraction steps. The second problem is that these reagents do not work well with crystalbound calcium. In our trials on BCP crystal quantification using the Phosphonazo III reagent, a very low and nonlinear response in colour change/amount of HA was observed. Therefore full conversion of BCP crystals into ions would be necessary for any type of colorimetric/spectrophotometric tests. And the third problem is that there are free ions already present in the matrix, which could contribute to the resultant absorbance. In the case of calcium, it can exist in three forms in biological fluids: ionised, protein-bound and complexed (with anions). It has been reported that the use of total calcium is unreliable in cases where there is a possible change in the protein-calcium binding characteristics or a decrease/increase in $\mathrm{pH} .{ }^{165}$

For the same reasons as above, methods such as the application of calciumselective electrodes and elemental analysis by atomic absorption or atomic emission would only be practical if the crystals are fully ionised, if non-crystal-related background ions are taken into account and if interferences are minimised.

X-Ray diffraction methods. For X-ray fluorescence (XRF) analysis, the sample material is irradiated with X-rays, which excite secondary X-ray fluorescence. The secondary X-rays have wavelengths characteristic of the elements of the sample and intensities proportional to their concentrations. The separation of individual wavelengths of the fluorescent X-ray emission is done by Bragg diffraction from crystals of specific lattice spacings. The advantages of XRF in comparison with wet chemical methods are the accurate analysis of samples that contain minerals, which are difficult to dissolve, or which are unstable in solution.

$\mathrm{X}$-Ray diffraction (XRD) is a nondestructive method, which is widely applied for the characterisation of crystalline materials. A beam of X-rays is directed at the finely powdered sample and are scattered in directions that depend on the crystal structure. The resulting X-ray diffraction pattern is unique for that crystalline material. XRD is a commonly used method for characterisation of all kinds of minerals, including calcium phosphates. ${ }^{166}$ For instance, to identify calcium phosphate crystals that are either too small, or too few in number to be identified by conventional light microscopy techniques, Swan et al. examined material extracted from the synovial fluid samples using electron microscopy and X-ray powder diffraction. ${ }^{35}$ The BCP clusters and CPPD crystals were found in 11 out of $12 \mathrm{OA}$ analysed samples and their origin confirmed by both energy dispersive Xray (EDX) analysis and $\mathrm{XRD}$. In one rheumatoid arthritis patient sample, BCP crystals were also identified.

Capillary electrophoresis. Capillary electrophoresis is a relatively new analytical technique that has begun to have an impact in the clinical laboratory. Its potential for automated, rapid, highefficiency separations makes it appealing as a replacement for some of the more labour-intensive assays carried out in gels and as a complement to companion techniques such as HPLC. ${ }^{167}$

Capillary electrophoresis has been used for the analysis of glycoproteins and glycosaminoglycans in synovial fluid. ${ }^{168-170}$ The technique has also been employed for pattern recognition between samples and observations of changes in the pattern of protein expression for rheumatoid disorders and osteoarthritis. ${ }^{171-173}$ Duffy et al. investigated characteristic changes in composition between normal human synovial fluid and fluid from clinically well-defined cases of OA and rheumatoid arthritis. ${ }^{174}$ Changes in a few distinctive characteristic peaks such as hyaluronan and uric acid for normal, osteoarthritic and rheumatoid synovial fluids were identified (Fig. 14).

Relative peak areas for these and other components varied in a systematic manner with disease state. Such pattern evaluation claimed to be suitable for statistical evaluation of the disease type based just on simple examination of the electropherogram.

Radioassay. Halverson and McCarty applied a semi-quantitative technique to detect calcium-containing crystals, predominantly $\mathrm{HA}$, in human synovial fluid samples employing $\left({ }^{14} \mathrm{C}\right)$ ethane1-hydroxy-1,1-diphosphonate (EHDP) binding. ${ }^{175}$ Binding material was found in $29 \%$ of non-inflammatory and in none of the inflammatory joint fluids. Synthetic CPPD crystals showed little affinity to $\left({ }^{14} \mathrm{C}\right)$ EHDP even at much higher concentrations than HA. Nevertheless in OA patient samples, nuclide binding material also correlated with the presence of CPPD crystals (that were identified by phase-polarised light microscopy). This finding could support the fact that both types of crystals (BCP and CPPD) may co-exist in severe degenerative processes.

Ferrography. Ferrography was originally designed to monitor wear and tear in machines such as car engines, where the engine oil lubricating the engine is examined by this technique for ferrous particles, which if present would indicate wear in the engine. These iron particles are obviously susceptible to an external magnetic field. It was proposed that ferrography could be used in an analogous way to investigate wear and tear in joints, where the synovial fluid lubricating the joint (natural or artificial) is examined by this technique for particles, which if present would indicate breakdown of the cartilage and/or the joint itself. ${ }^{176,177}$ Ferrography has great potential for the study of OA where mechanical wear of the joint surface occurs. ${ }^{178}$

Evans et al. ${ }^{179}$ adapted this method for the study of cartilaginous and osseous wear particles, as well as fragments of soft tissue found in the synovial fluid of human joints. As most biological materials are not magnetic, samples were magnetised with a solution containing the trivalent paramagnetic cation of the rare earth element erbium. Because erbium interacts strongly with most substances in synovial fluid producing troublesome precipitates, additional purification steps using saline and hyaluronidase were employed for successful analysis. ${ }^{180}$ It was demonstrated that using this technique, improved diagnosis of arthritis might be possible based 

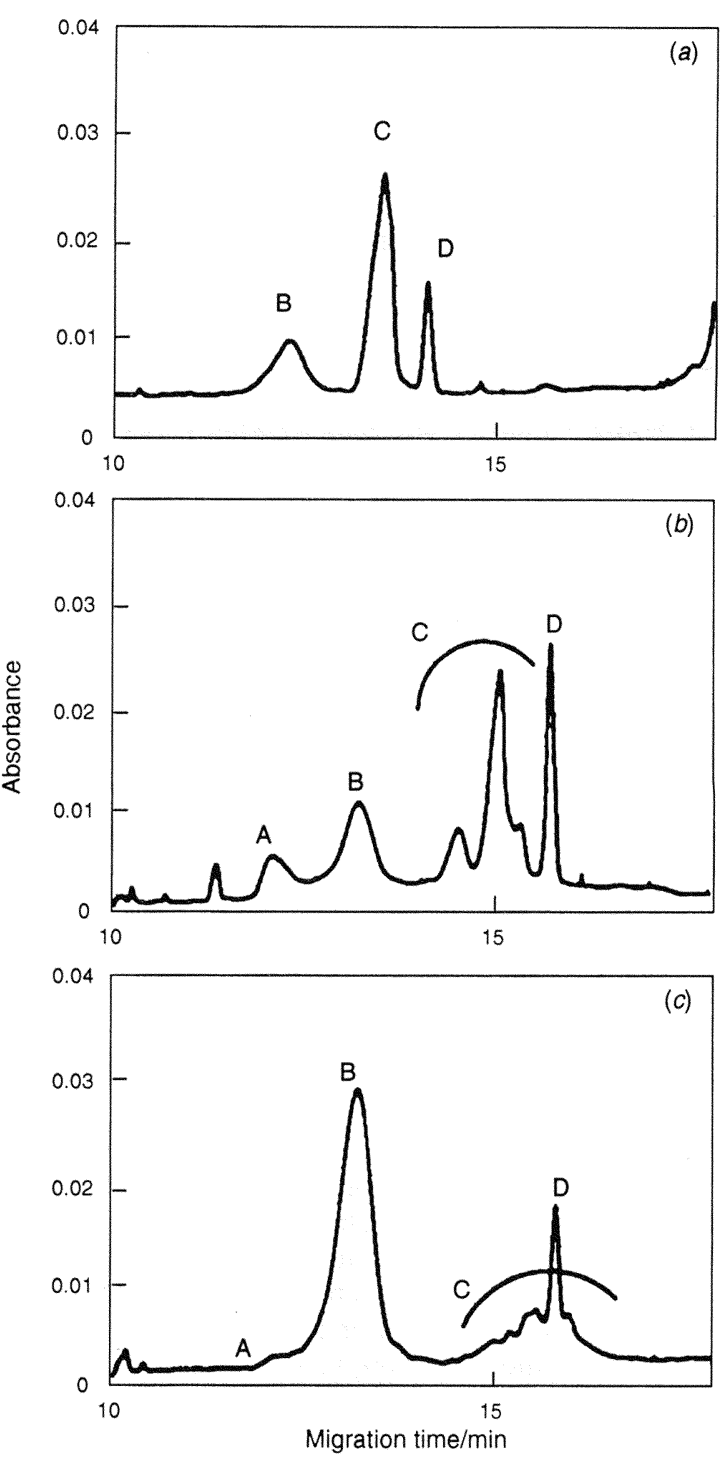

Fig. 14 Capillary electropherograms of human synovial fluid: (a) normal sample; (b) osteoarthritis; (c) rheumatoid arthritis. A and B: unidentified substances; C: presumably hyaluronan, D: uric acid. Reproduced with permission from ref. 174. (Copyright 1994, Royal Society of Chemistry.)

on the examination of separated particles. To identify the particles, ferrograms may be inspected by light microscopy methods, SEM and X-ray analysis.

In 1997, Podsiadlo et al. employed SEM to study particles extracted from synovial fluid samples by ferrography and to examine how they might be related to the severity of OA. ${ }^{181}$ Significant differences were found between the numerical descriptors calculated for wear particles from healthy and osteoarthritic knee joints (the boundary fractal dimension, shape factor, convexity and elongation), suggesting that the particle shape can be used as an indicator of the joint condition, i.e. in the diagnosis and prognosis of joint diseases. In particular, the fractal dimension of the particle boundary was shown to correlate directly with the degree of OA.

\section{Extraction methods for BCP}

It is often a requirement for certain analytical methods to work with purified samples. This is because the very complex and viscous synovial fluid matrix can easily 'hide' the pathogenic crystals, which complicates microscopic examina- tion and/or the use of other sensitive instrumental methods. Purification is especially important in scanning electron microscopy (SEM) and atomic force microscopy (AFM). Another reason for performing an extraction prior to analysis of the crystals is that as well as BCP, CPPD, MSU and CO crystals, synovial fluid can contain other crystalline-like structures such us cholesterol, lipid particles and other artefacts. Even talc particles or prior corticosteroid injections can result in a false positive sighting for crystals. ${ }^{182}$ Protein coating of crystals is also an issue as it may alter the observed crystal habitat. This can result in unusual surfaces on the crystals, causing changes to the absorption of X-ray spectra, and thus altering the elemental ratio. ${ }^{183}$ Hence, removal of the biological material before examination of the crystals is often necessary.

BCP crystals can be isolated from synovial fluid using a chemical and/or enzymatic approach. The use of hydrazine is a commonly used method for deproteination of the crystals and it induces only minor chemical changes and no structural changes of the mineral phase HA. ${ }^{184}$ Cunningham et al. examined a series of synovial fluid samples spiked with various HA concentrations (by the addition of increasing masses of synthetic HA crystals with a particle size of less than $37 \mu \mathrm{m}$ ) and treated them with $100 \%$ hydrazine. ${ }^{109}$ After mixing for $15 \mathrm{~min}$ and incubation for $12 \mathrm{~h}$ the paired samples were centrifuged, dried and analysed by X-ray diffraction. The use of an equal volume of synovial fluid and hydrazine was optimal for the detection of $\mathrm{HA}$, as the characteristic hydroxyapatite bands were only visible in the hydrazinetreated samples.

Halverson and McCarty mixed the synovial fluid samples with hyaluronidase prior to identification of HA crystals in synovial fluid. ${ }^{175}$ McCarty also reported a multi-step purification procedure for extraction of CPPD crystals from synovial fluid. ${ }^{185}$ Crystals were pelleted by centrifugation after hyaluronidase treatment of the fluid, the cells in the pellet ruptured by freeze-thawing, the lipid removed with ether and the protein by trypsin digestion. The relatively concentrated solid material revealed characteristic IR absorption bands for CPPD.

To extract and concentrate calciumcontaining crystals, Swan et al. used a protocol where the synovial fluid and articular 
cartilage samples were treated with papain and sodium hypochlorite. ${ }^{186}$ They demonstrated the ability to re-extract spiked synthetic CPPD and HA crystals from the samples in an unchanged form and they found concentrations of the crystals in synovial fluid to be higher than previously published figures.

Moradi-Bidhendi and Turner reported that treatment of synovial fluid samples with a $2.6 \%$ solution of sodium hypochlorite followed by washing steps with HAsaturated distilled water and $99 \%$ ethanol was sufficient to give good recovery of the HA crystals. ${ }^{108}$ This was confirmed by scanning electron microscopy.

Ultra-sonication has been reported to improve crystal purification process from synovial fluid. ${ }^{187}$

Most of the above-mentioned techniques can provide good recovery of synthetic HA or CPPD crystals that have been added/spiked into synovial fluid. This provides evidence that these methods may be applicable for BCP crystal extraction from real osteoarthritic samples. However, pathogenic BCP crystals differ from synthetic crystals, especially with respect to particle size and the distribution of surface charges, so the purification of such crystals may be a more complicated task in real patient samples.

\section{Conclusions}

Osteoarthritis is a prevalent disease that has a significant negative impact on both the patient and on society as a whole. While there are many reports in the literature about this condition, especially from a clinical point of view, there is still much work to do in order to fully understand the causes and development of the disease.

Basic calcium phosphate (BCP) crystals are unique to osteoarthritis and represent a possible therapeutic target. However, their small size and the complex synovial fluid matrix renders them difficult to detect. It is clear that traditional microscopic methods are too subjective to be relied upon as a tool for detecting BCP crystals. More advanced microscopic techniques such as scanning electron microscopy and atomic force microscopy, which are not readily available and are expensive, have the advantage of resolution but the crystals must first be isolated from the synovial fluid for accurate work. MRI, X-ray and ultrasound offer advanced imaging capabilities of joint damage from crystal deposition but do not have the sensitivity to differentiate between crystal types. Fluorescent imaging dyes are available only for use in animal models at the moment but may be used for human osteoarthritic joints in the future. Spectroscopic methods, especially Raman, offer the means to distinguish between crystals and other artefacts and these instruments are now more readily available in analytical laboratories. Differences in infrared spectra from patient synovial fluids has proved useful for categorising samples into disease states. Other techniques such as ferrography, radioassay and capillary electrophoresis have also been reported but have not been widely implemented. Elemental analysis is useful for the quantitative analysis of the components of calcium phosphate crystals but the crystals need to be dissociated prior to this type of assay.

In summary, selective approaches will be required in order to be able to work with BCP crystals effectively. We believe that modified bisphosphonates have the potential to be exploited for the detection and even for quantitation in this context. As analytical scientists, we need to strive to develop these methods and make them available in the clinical setting since without the means to detect and quantify BCP crystals, we will never know if we can control and perhaps even prevent osteoarthritis in the future.

\section{Acknowledgements}

The authors would like to acknowledge the Wellcome Trust for funding this osteoarthritis research.

\section{References}

1 The Health of the Nation, Vhi Healthcare Press Release. Published at: www.vhi.ie/press/100406.jsp (accessed 11 Jan 2008).

2 I. F. Peterson, Ann. Rheum. Dis., 1996, 55, 659-661.

3 J. Bijlsma and K. Knahr, Best Pract. Res. Clin. Rheumatol., 2007, 21, 59-76.

4 A. Malviya and A. McCaskie, Medicine, 2006, 34, 369-372.

5 R. D. Altman, E. Abadie, B. Avouac, G. Bouvenot, J. Branco, O. Bruyere, G. Calvo, J.-P. Devogelaer, R. L. Dreiser, G. Herrero-Beaumont, A. Kahan, G. Kreutz, A. Laslop, E. M. Lemmel, C. J. Menkes, K. Pavelka, L. Van De Putte, L. Vanhaelst and J.-Y. Reginster, Osteoarthr. Cartilage, $2005,13,13-19$.
6 D. T. Felson, R. C. Lawrence, M. C. Hochberg, T. McAlindon, P. A. Dieppe, M. A. Minor, S. N. Blair, B. M. Berman, J. F. Fries, M. Weinberger, K. R. Lorig, J. J. Jacobs and V. Goldberg, Ann. Intern. Med., 2000, 133, 726-737.

7 H. A. Bird, Clin. Rheumatol., 2003, 22, 165-167.

8 G. McCarthy and P. Dieppe, Ann. Rheum. Dis., 1999, 58, 723.

9 I. Uthman, J.-P. Raynauld and B. Haraoui, Postgrad. Med. J., 2003, 79, 449-453.

10 A. Jones and M. Doherty, Ann. Rheum. Dis., 1996, 55, 829-832.

11 N. Gerwin, C. Hops and A. Lucke, $A d v$. Drug Delivery Rev., 2006, 58, 226-242.

12 T. Karachalios, H. A. Karantanas and K. Malizos, Eur. J. Radiol., 2007, 63, 3648.

13 I. Watt, Ann. Rheum. Dis., 1983, 42, S73S80.

14 A. J. Grainger and D. McGonagle, Imaging, 2003, 15, 286-297.

15 Jr. Adams, P. R. Herz, D. L. Stamper, M. J. Roberts, S. Bourquin, N. A. Patel, K. Schneider, S. D. Martin, S. Shortkroff, J. G. Fujimoto and M. E. Brezinski, J. Orthop. Res., 2006, 24, 708-715.

16 R. Hinton, R. L. Moody, A. W. Davis and S. F. Thomas, Am. Fam. Physician., 2002, 65, 841-848.

17 G. Bálint and B. Szebenyi, Drugs, 1996, 52(Suppl 3), 1-13.

18 C. W. Wu, M. R. Morrell, E. Heinze, A. L. Concoff, S. J. Wollaston, E. L. Arnold, R. Singh, C. Charles, M. L. Skovrun, J. D. FitzGerald, L. W. Moreland and K. C. Kalunian, Semin. Arthritis Rheum., 2005, 35, 197-201.

19 Y. Kumon, T. Suehiro, K. Nishiya, K. Hashimoto, K. Nakatani and J. D. Sipe, Amyloid, 1999, 6, 130-135.

20 C. Belcher, R. Yaqub, F. Fawthrop, M. Bayliss and M. Doherty, Ann. Rheum. Dis., 1997, 56, 299-307.

21 E. J. Thonar, K. Masuda, M. E. Lenz, H. J. Hauselmann, K. E. Kuettner and D. H. Manicourt, J. Rheumatol. Suppl., 1995, 43, 68-70.

22 B. M. Praest, H. Greiling and R. Kock, Clin. Chim. Acta, 1997, 266, 117-128.

23 I. G. Otterness and M. J. Saltarelli, in Modern therapeutics in rheumatic diseases, ed. G. C. Tsokos, Humana Press, Totowa, NJ, 2001, pp. 215-236.

24 D. D. Frisbie and C. W. McIlwraith, $A A E P$ Proc., 2001, 47, 211-216.

$25 \mathrm{~S}$. Nalbant, J. A. Martinez, T. Kitumnuaypong, G. Clayburne, M. Sieck and H. R. Schumacher, Jr., Osteoarthr. Cartilage, 2003, 11, 50-54.

26 A. K. Rosenthal, Curr. Opin. Rheumatol., 2007, 19, 158-162.

27 N. Olmez and H. R. Schumacher, Jr., Curr. Rheumatol. Rep., 1999, 1, 107-111.

28 M. H. Choi, J. D. McKenzie and M. K. Dalinka, Rheum. Dis. Clin. North Am., 2006, 32, 427-446.

29 I. Maldonado, V. Prasad and A. J. Reginato, Curr. Rheumatol. Rep., 2002, 4, 257-264.

30 B. Derfus, S. Kranendonk, N. Camacho, N. Mandel, V. Kushnaryov, K. Lynch and L. Ryan, Calcif. Tissue Int., 1998, 63, 258262. 
31 M. Heger, S. Mordon, G. Leroy, L. Fleurisse and C. Creusy, J. Biomed. Opt., 2006, 11, 024003.

32 A. Rosenthal, Rheum. Dis. Clin. North Am., 2006, 32, 401-412.

33 L. C. Whelan, M. P. Morgan and G. M. McCarthy, Front. Biosci., 2005, 10, 530541.

34 P. A. Gibilisco, H. R. Schumacher, J. L. Hollander and K. A. Soper, Arthritis Rheum., 1985, 28, 511-515.

35 A. Swan, B. Chapman, P. Heap, H. Seward and P. Dieppe, Ann. Rheum. Dis., 1994, 53, 467-470.

36 E. S. Molloy and G. M. McCarthy, Curr. Opin. Rheumatol., 2006, 18, 187-192.

37 F. D. O'Shea and G. M. McCarthy, Curr. Opin. Rheumatol., 2004, 16, 273-278.

38 N. W. McGill, Best Pract. Res. Clin. Rheumatol., 2000, 14, 445-460.

39 R. W. Moskowitz, B. K. Harris, A. Schwartz and G. Marshall, Arthritis Rheum., 1971, 14, 109-116.

40 D. J. McCarty, P. B. Halverson, G. F. Carrera, B. J. Brewer and F. K. Kozin, Arthritis Rheum., 1981, 24, 464-473.

41 M. P. Morgan and M. McCarthy, Curr. Opin. Rheumatol., 2002, 14, 292-297.

42 E. S. Molloy and G. M. McCarthy, Curr. Rheumatol. Rep., 2004, 6, 228-234.

43 P. A. Dieppe, D. V. Doyle, E. C. Huskisson, P. R. Crocker and A. Willoughby, Lancet, 1976, 1(7954), 266-269.

44 H. R Schumacher, Am. J. Med., 1996, 100, $46 \mathrm{~S}-52 \mathrm{~S}$

$45 \mathrm{H}$. Ishikawa, Y. Ueba, T. Isobe and K. Hirohata, Rheumatol. Int., 1987, 7, $217-$ 221.

46 J. A. Freemont and J. Denton, in Rheumatology, ed. M. C. Hochberg, A. J. Silman, J. S. Smolen, M. E. Weinblatt and M. H. Weisman, Mosby, St. Louis, MO, 3rd edn, 2003, vol. 1, section 2, pp. $1-5$.

$47 \mathrm{M}$. Carvalho and M. A. Vieira, Int. Braz. J. Urol., 2004, 30, 205-208.

48 L. A. Rubin, K. P. H. Pritzker, P.-T. Cheng and A. G. Fam, Ann. Rheum. Dis., 1983, 42, 213-215.

49 P. B. Halverson, H. S. Cheung, R. Johnson and J. Struve, Clin. Orthop. Relat. Res., 1990, 257, 162-165.

50 G. M. McCarthy, Curr. Rheumatol. Rep., 1999, 1, 101-106.

51 H. S. Cheung, J. D. Sallis, K. D. Demadis and A. Wierzbicki, Arthritis Rheum., 2006, 54, 2452-2461.

52 M. A. E. Zagaria, US Pharm., 2006, 1, 20 24.

53 M. Fajardo and P. E. Di Cesare, Drugs Aging, 2005, 22, 141-161.

54 F. Martini and E. F. Bartholomew, Essentials of Anatomy \& Physiology, Pearson, Reading, 4th edn, 2006.

55 C. R. Kjeldsberg and J. A. Knight, Body Fluids: Laboratory Examination of Amniotic, Cerebrospinal, Seminal, Serous and Synovial Fluids, American Society for Clinical Pathology, Chicago, IL, 3rd edn, 1993.

56 R. J. Trudnowski and R. C. Rico, Clin. Chem. (Washington, D. C. ), 1974, 20,615616.

57 E. George, Ann. Rheum. Dis., 1998, 57, 637-640.
58 J. Karlsson, L. S. Sjögren and L. S Lohmander, Rheumatology, 2002, 41, 1240-1248

59 M. D. Grynpas and S. Omelon, Bone, 2007, 41, 162-164.

60 R. Lagier and C.-A. Baud, Pathol. Res Pract., 2003, 199, 329-335.

61 Published at www.azom.com/details.asp? ArticleID=2140 (accessed 11 Jan 2008).

62 C. P. Klein, J. M. de Blieck-Hogervorst, J. G. Wolke and K. de Groot, Biomaterials, 1990, 11, 509-512.

63 E. S. Molloy and G. M. McCarthy, Curr. Rheumatol. Rep., 2003, 5, 215-221.

64 D. J. McCarty, J. R. Lehr and P. B. Halverson, Arthritis Rheum., 1983, 26, 1220-1224.

65 W. A. House, Environ. Technol., 1999, 20 727-733.

$66 \mathrm{H}$. McDowell, W. E. Brown and J. R Sutter, Inorg. Chem., 1971, 10, 1638-1643.

67 L. C. Chow, in Octacalcium Phosphate, ed. L. C. Chow and E. D. Eanes, Monograph in Oral Science, Karger, Basel, 2001, vol. 18, pp. 94-111.

68 J. L. Meyer and G. H. Nancollas, Arch. Oral Biol., 1972, 17, 1623-1627.

69 P. Dieppe, J. Hornby, A. Swan, C. Hutton and A. Preece, Ann. Rheum. Dis., 1983, 42 60-63.

70 R. Murugan and S. Ramakrishna, J. Cryst. Growth, 2005, 274, 209-213.

71 S. Zhang, G. Gangal and H. Uludag, Chem. Soc. Rev., 2006, 36, 507-531.

72 G. Daculsi, R. Z. LeGeros and D. Mitre, Calcif. Tissue Int., 1989, 45, 95-103.

73 A. J. Freemont, J. Denton, A. Chuck, P. J. Holt and M. Davies, Ann. Rheum. Dis. 1991, 50, 101-107.

74 C. Gordon, A. Swan and P. A. Dieppe, Ann. Rheum. Dis., 1989, 48, 737-742.

75 P. Dieppe and A. Swan, Ann. Rheum. Dis., 1999, 58, 261-263.

76 E. Pascual, J. Tovar and M. T. Ruiz, Ann. Rheum. Dis., 1989, 48, 983-985.

77 P. R. Hearn, D. F. Guilland-Cumming and R. G. G. Russell, Ann. Rheum. Dis., 1983, 42, 107-108.

78 J. Ivorra, J. Rosas and E. Pascual, Ann. Rheum. Dis., 1999, 58, 582-584.

79 H. R. Schumacher, M. S. Sieck, C. Rothfuss, G. M. Clayburne, D. F Baumgarten and B. S. Mochan, Arthritis Rheum., 1986, 29, 770-774.

80 N. W. McGill and H. York, Aust. NZ J. Med., 1991, 34, 710-713.

81 P. Hasselbacher, Arthritis Rheum., 1987, 30, 637-642.

82 E. Pascual and V. Jovan 1 , Best Pract. Res. Clin. Rheumatol., 2005, 19, 371-386.

83 G. M. McCarthy, Curr. Opin. Rheumatol., 2005, 17, 312-313.

84 J. Segal and D. Albert, Am. Coll. Rheumatol., 1999, 12, 376-380.

85 B. Lumbreras, E. Pascual, J. Frasquet, J. González-Salinas, E. Rodríguez and I. Hernández-Aguado, Ann. Rheum. Dis. 2005, 64, 612-615.

$86 \mathrm{R}$. von Essen, A. Holtta and R Pikkarainen, Ann. Rheum. Dis., 1998, 57, 107-109.

87 K. Jaovisidha and A. K. Rosenthal, Curr Opin. Rheumatol., 2002, 14, 298-302.

88 H. Paul, A. J. Reginato and R. Schumacher, Arthritis Rheum., 1983, 26, 191-200.
89 F. Eggelmeijer, B. A. Dijkmans, J. D Macfarlane and A. Cats, Clin. Exp. Rheumatol., 1991, 9, 11-16.

90 E. Ortiz-Bravo, Rev. Prat., 1994, 44, 174 177.

91 Ph. R. Krey and D. M. Lazaro, in Analysis of synovial fluid, ed. K. D. Brandt, Summit, NJ, Ciba-Geigy, 1992, p. 32.

92 J.-W. Huang, W.-J. Chen, S.-K. Liao, C.-Y. Yang, S.-S. Lin and C.-C. Wu, Chang Gung Med. J., 2006, 29, 363-372.

93 K. Shoji, Nippon Seikeigeka Gakkai Zasshi, 1993, 67, 201-210.

$94 \mathrm{Ph}$. R. Krey and D. M. Lazaro, in Analysis of synovial fluid, ed. K. D. Brandt, Summit, NJ, Ciba-Geigy, 1992, pp. 34-35.

95 O. Lazcano, C. Li, R. V. Pierre, J. D o'Duffy, R. S. Beissner and P. C. AbellAleff, Am. J. Clin. Pathol., 1993, 99, 90-96.

96 E. Selvi, S. Manganelli, M. Catenaccio, R. de Stefano, E. Frati, S. Cucini and R. Marcolongo, Ann. Rheum. Dis., 2001, 60 , 194-198.

97 A. Petrocelli, A. L. Wong and L. Swezy, J. Clin. Rheumatol., 1998, 4, 103-105.

98 M. Krutsy, Acta Histochem., 1963, 15, 189-191.

99 G. Raustyte, P. Cayé-Thomasen, A. Hermansson, H. Andersen and J. Thomsen, Int. J. Pediatr. Otorhinolaryngol., 2006, 70, 529-539.

100 C. E. Bills, H. Eisenberg and S. L. Pallante, Johns Hopkins Med. J., 1974, 128, 194 207.

101 M. Asselman, A. Verhulst, M. E. de Broe and C. F. Verkoelen, J. Am. Soc. Nephrol., $2003,14,3155-3166$

102 F. Bonewald, S. E. Harris, J. Rosser, M. R. Dallas, S. L. Dallas, N. P. Camacho, B. Boyan and A. Boskey, Calcif. Tissue Int., 2003, 72, 537-547.

103 Y. X. Huang, Curr. Appl. Phys., 2005, 5, $553-556$.

104 Z.-G. Zha, C.-C. Yao, M. Tu and Y.-X. Huang, Curr. Appl. Phys., 2007, 7(S1), 112115 .

105 D. L. Gardner, D. McGovern Salter and K. Oates, Microsc. Res. Technol., 1997, 37, 245-270.

106 M. C. Owellen, M.Sc. Thesis, Virginia Polytechnic Institute and State University, 1997.

107 A. Hayes, I. G. Turner, K. A. Powell and P. A. Dieppe, J. Mater. Sci.: Mater. Med., 1992, 3, 75-78.

108 N. Moradi-Bidhendi and I. G. Turner, J. Mater. Sci.: Mater. Med., 1995, 6, 5155.

109 T. Cunningham, D. Uebelthart, J. M. Very, G. H. Fallet and T. L. Visher, Ann. Rheum. Dis., 1989, 48, 829-831.

110 T. Bardin, B. Bucki, J. Lansaman, E. OrtizBravo, A. Ryckewaert and A. Dryll, Rev. Rhum. Mal. Osteoartic., 1987, 54, 149 154.

111 D. V. Doyle and P. R. Crocker, Ann. Rheum. Dis., 1983, 42, 108.

112 J. Li-Yu, G. M. Clayburne, M. S. Sieck, S. E. Walker, B. H. Athreya, R. J. de Horatius and H. R. Schumacher, Ann. Rheum. Dis., 2002, 61, 387-390.

113 S. Y. Ali, Scan. Electron Microsc., 1985, 4 1555-1566.

114 S. Y. Ali, A. Wisby and J. C. Gray, Metab. Bone Dis., 1978, 1, 97-103. 
115 L.-J. Zhang, X.-S. Feng, H.-G. Liu, D.-J. Qian, L. Zhang, X.-L. Yu and F.-Z. Cui, Mater. Lett., 2004, 58, 719-722.

116 R. S. Lee, M. V. Kayser and S. Y. Ali, J. Anat., 2006, 208, 13-19.

117 T. Bardin, H. R. Schumacher, J. Lansaman, S. Rothfuss and A. Dryll, Ann. Rheum. Dis., 1984, 43, 624-627.

118 H. R. Schumacher and P. V. Cherian, Scan. Electron Microsc., 1984, 2, 965-968.

119 J. A. Bonavita, M. K. Dalinka and H. R. Schumacher, Radiology, 1980, 134, 621625.

120 E. I. Suvorova and P. A. Buffat, Eur. Cells Mater., 2001, 1, 27-42.

121 P. Nero, I. Nogueira, R. Vilar, J. B. Pimentão and J. C. Branco, Acta Reumatol. Port., 2006, 31, 75-81.

122 J. M. Blair, L. B. Sorensen, M. F. Arnsdorf and R. Lal, Semin. Arthritis Rheum., 1995, 24, 359-369.

123 D. A. Smith, S. D. Connell, C. Robinson and J. Kirkham, Anal. Chim. Acta, 2003, 479, 39-57.

124 N. J. Pizzi and W. Pedrycz, 2004 Annual Meeting of the North American Fuzzy Information Processing Society, held 27-30 June 2004, Banff, Alberta, Canada, vol. 2, pp. 669-674.

125 J. Wang, M. Sowa, H. H. Mantsch, A. Bittner and H. M. Heise, TrAC, Trends Anal. Chem., 1996, 5, 286-296.

126 H. Gamze, O. Klein, G. Oremek and W. Mäntele, Anal. Bioanal. Chem., 2007, 387, $1815-1822$.

127 J.-C. Hornez, F. Chai, F. Monchau, N. Blanchemain, M. Descamps and H. F. Hildebrand, Biomol. Eng., 2007, 24, 505 509.

128 H. H. Eysel, M. Jackson, A. Nikulin, R. L. Somorjai, G. T. D. Thomson and H. H. Mantsch, Biospectroscopy, 1997, 3, 161167.

129 C. M. Ziegler, P. Kircher and S. Hassfeld, J. Oral. Maxillofac. Surg., 2002, 60, 13021306.

130 R. A. Shaw, H. H. Eysel, K. Z. Liu and H. H. Mantsch, Anal. Biochem., 1998, 259, 181-186.

131 R. A. Shaw, S. Kotowich, H. H. Eysel, M. Jackson, G. T. D. Thomson and H. H. Mantsch, Rheumatol. Int., 1995, 15, 159165.

132 R. A. Shaw and H. H. Mantsch, in Encyclopedia of Analytical Chemisty, ed. R. A. Meyers, John Wiley \& Sons Ltd, Chichester, 2000, vol. 1, pp. 83-102.

133 J. Dubois and R. A. Shaw, Anal. Chem., 2004, 76, 360A-367A.

134 J. S. Shah, Ann. Rheum. Dis., 1983, 42, S68S72.

135 Modern Raman Spectroscopy: A Practical Approach, ed. E. Smith and G. Dent, Wiley, Chichester, 2005, $210 \mathrm{pp}$.

136 A. Carden and M. D. Morris, J. Biomed. Opt., 2000, 5, 259-268.

137 H. P. Buschman, G. Deinum, J. T. Motz, M. Fitzmaurice, J. R. Kramer, A. von der Laarse, A. V. Bruschke and M. S. Feld, Cardiovasc. Pathol., 2001, 10, 6982.
138 G. Penel, C. Delfosse, M. Descamps and G. Leroy, Bone, 2005, 36, 893-901.

139 P. Matousek and N. Stone, J. Biomed. Opt., 2007, 12, 024008

140 N. McGill, P. A. Dieppe, M. Bowden, D. J. Gardiner and M. Hall, Lancet, 1991, 337, 77-78.

141 M. D. Morris and B. J. Roessler, Future Rheumatol., 2006, 1, 383-386.

142 S. C. Manolagas, Endocr. Rev., 2000, 21, 115-137.

143 A. Zaheer, R. E. Lenkinski, A. Mahmood, A. G. Jones, L. C. Cantley and J. V. Frangioni, Nat. Biotechnol., 2001, 19, $1148-1154$.

144 J. V. Frangioni, US Pat., 6869 593, 2005.

145 R. E. Lenkinski, A. Muneeb, Z. Atif, J. V. Frangioni and S. N. Goldberg, Acad. Radiol., 2003, 10, 1159-1164.

146 S. Kossodo, C. Erickson S. Carlson and H. Alaoui, Poster Session 113, Society for Molecular Imaging Annual Meeting, Cologne, Germany, 2005.

147 Y. Zilberman, I. Kallai, Y. Gafni, G. Pelled, S. Kossodo, W. Yared and D. Gazit, J. Orthop. Res., 2007, DOI: 10.1002/ jor.20518.

148 A. M. De Grand, S. J. Lomnes, D. S. Lee, M. Pietrzykowski, S. Ohnishi, T. G. Morgan, A. Gogbashian, R. G. Laurence and J. V. Frangioni, J. Biomed. Opt., 2006, 11, 014007.

149 L. V. Hale, Y. F. Ma and R. F. Santerre, Calcif. Tissue Int., 2000, 67, 80-84.

150 G. I. Kieft, D. J. Sartoris, J. L. Bloem, P. C. Hajek, L. L. Baker, D. Resnick, W. R. Obermann, P. Rozing and J. Doornbos, Skeletal Radiol., 1987, 16, 285-290.

151 G. Reid and J. M. Esdaile, JAMC, 2000, 162, 1318-1325.

152 J. W. Orchard, J. W. Read and I. F. Anderson, Med. J. Aust., 2005, 183, 482 486.

153 G. Clunie, M. A. Hall-Craggs, M. N. Paley, A. King, I. D. Wilkinson, P. J. Ell and J. C. W. Edwards, Ann. Rheum. Dis., 1997, 56, 526-534.

154 C. Heron, Br. J. Hosp. Med., 1994, 51, $97-$ 101.

155 G. J. Kieft, B. A. Dijkmans, J. L. Bloem and H. M. Kroon, Ann. Rheum. Dis., 1990, 49, 7-11.

156 L. Brunton, M. Anderson, M. Pannunzio, A. Khanna and A. Chhabra, J. Hand Surg., 31, 1001-1011.

157 D. G. Gillies, B. Newling and E. W. Randall, J. Magn. Reson., 2001, 151, 235 241.

158 J. L. Ackerman, D. P. Raleigh and M. J. Glimcher, Magn. Reson. Med., 25, 1-11.

159 N. Radin and A. L. Gramza, Clin. Chem. (Washington, D. C.) , 1964, 10, 704-720.

160 S. A. Cohen and L. Sideman, Clin. Chem. (Washington, D. C.), 1979, 25, 1519.

161 P. Palade and J. Vergara, Biophys. J., 1983, 43, 355-369

162 B. R. Morgan, J. D. Artiss and B. Zak, Clin. Chem. (Washington, D. C.), 1993, 39, 1608-1612.

163 Z. He and C. W. Honeycutt, Commun. Soil Sci. Plan., 2005, 36, 1373-1383.
164 D. F. Boltz and J. A. Howell, Colorimetric Determination of Nonmetals, Wiley Interscience Publication, Toronto, 2nd edn, 1978, pp. 338-367.

165 J. R. Petersen, K. U. Onifade, A. A. Mohammad and A. O. Okorodudu, J. Lab. Med., 2005, 29, 235-240.

166 A. R. Calafiori, G. Di Marco, G. Martino and M. Marotta, J. Mater. Sci.: Mater. Med., 2007, 18, 2331-2338.

167 P. Landers, Clin. Chem. (Washington, D. C. ), 1995, 41, 495-509.

168 A. Korneluk-SadzyÄska, B. Mierzejewska-Iwanowska, K. Zwierz and J. Popko, Med. Sci. Monit., 1999, 5, 1191-1196.

169 A. Rice, J. Grimshaw, J. Trocha-Grimshaw, P. McCarron and G. B. Wisdom, J. Chromatogr., A, 1997, 6, 305-311.

170 J. Grimshaw, J. Trocha-Grimshaw, W. Fisher, A. Rice, S. Smith, P. Spedding, J. Duffy and R. Mollan, Electrophoresis, 1996, 17, 396-400.

171 L. Willumsen and J. Friis, Scand. J. Rheumatol., 1975, 4, 234-240.

172 E. G. Nettelbladt and L. K. M. Sundblad, Arthritis Rheum., 1959, 2, 144-151.

173 K. Fujimura, N. Segami, Y. Yoshitake, N. Tsuruoka, K. Kaneyama, J. Sato and S. Kobayashi, Oral Surg., Oral Med., Oral Pathol., Oral Radiol., Endodontol., 2006, 101, 463-468.

174 J. M. Duffy, J. Grimshaw, A. Kane, R. A. B. Mollun, P. L. Spedding and J. TrochaGrimshaw, Anal. Proc., 1994, 31, 257259

175 P. B. Halverson and D. J. McCarty, Arthritis Rheum., 1979, 22, 389-395.

176 I. Hirose, Nippon Seikeigeka Gakkai Zasshi, 1991, 65, 1045-1059.

177 D. C. Mears, E. N. Hanley, Jr., R. Rutkowski and V. C. Westcott, J. Biomed. Mater. Res., 1978, 12, 867-875.

178 M. S. Kuster, P. Podsiadlo and G. W. Stachowiak, Rheumatology, 1998, 37, 978984.

179 C. H. Evans, E. R. Bowen, J. Bowen, W. P. Tew and V. C. Westcott, J. Biochem. Biophys. Methods, 1980, 2, 11-18.

180 C. H. Evans and D. C. Mears, Bull. Prosthet. Res., 1981, BPR 10-36, 13-26.

181 P. Podsiadlo, G. W. Stachowiak and M. Kuster, Wear, 1997, 210, 318-325.

182 S. R. Brannan and D. A. Jerrard, J. Emerg. Med., 2006, 30, 331-339.

183 P. A. Dieppe, P. R. Crocker, C. F. Corke, D. V. Doyle, E. C. Huskisson and D. A. Willoughby, Q. J. Med., 1979, 48, 533-553.

184 J. D. Termine, E. D. Eanes, D. J. Greenfield, M. U. Nylen and R. A. Harper, Calcif. Tissue Res., 1973, 12, 73-90.

185 D. J. McCarty, Ann. Rheum. Dis., 1983, 42, 243-253.

186 A. J. Swan, B. R. Heywood and P. A. Dieppe, J. Rheumatol., 1992, 19, $1763-$ 1773 .

187 M. J. Olszta, X. Cheng, S. S. Jee, R. Kumar, Y.-Y. Kim, M. J. Kaufman, E. P. Douglas and L. B. Gower, Mater. Sci. Eng., 2007, 58, 77-116. 